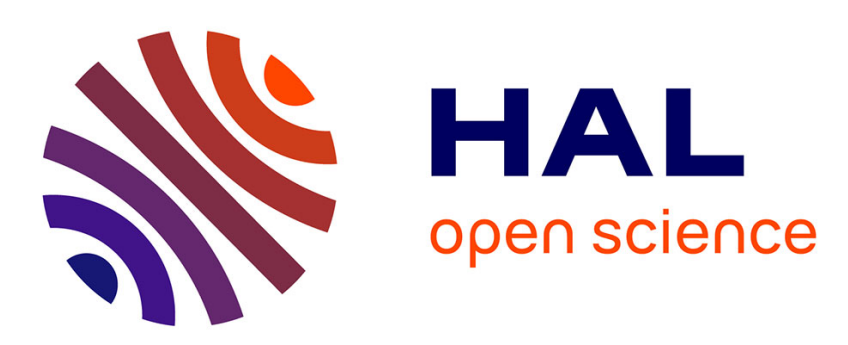

\title{
Correlates of complete brood failure in blue tits: could extra-pair mating provide unexplored benefits to females?
}

Adèle Mennerat, Anne Charmantier, Christian Jorgensen, Sigrunn Eliassen

\section{- To cite this version:}

Adèle Mennerat, Anne Charmantier, Christian Jorgensen, Sigrunn Eliassen. Correlates of complete brood failure in blue tits: could extra-pair mating provide unexplored benefits to females?. Journal of Avian Biology, 2018, 49 (5), 10.1111/jav.01701 . hal-02327900

\section{HAL Id: hal-02327900 \\ https://hal.science/hal-02327900}

Submitted on 23 Oct 2019

HAL is a multi-disciplinary open access archive for the deposit and dissemination of scientific research documents, whether they are published or not. The documents may come from teaching and research institutions in France or abroad, or from public or private research centers.
L'archive ouverte pluridisciplinaire HAL, est destinée au dépôt et à la diffusion de documents scientifiques de niveau recherche, publiés ou non, émanant des établissements d'enseignement et de recherche français ou étrangers, des laboratoires publics ou privés. 


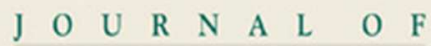

Avian Biology

\section{Correlates of complete brood failure in blue tits: could extra-pair mating provide unexplored benefits to females?}

\begin{tabular}{|c|l|}
\hline Journal: & Journal of Avian Biology \\
\hline Manuscript ID & JAV-01701.R2 \\
\hline Keywords: & multiple mating, passerine bird, promiscuity \\
\hline & $\begin{array}{l}\text { Behavioural ecologists have for decades investigated the adaptive value of } \\
\text { extra-pair copulation (EPC) for females of socially monogamous species. } \\
\text { Despite extensive effort testing for genetic benefits, there now seems to be } \\
\text { a consensus that the so-called 'good genes' effects are at most weak. In } \\
\text { parallel the search for direct benefits has mostly focused on the period } \\
\text { surrounding egg laying, thus neglecting potential correlates of EPC that } \\
\text { might be expressed at later stages in the breeding cycle. Here we used } \\
\text { Bayesian methods to analyse data collected over four years in a population } \\
\text { of blue tits (Cyanistes caeruleus), where no support was previously found } \\
\text { for 'good genes' effects. We found that broods with mixed paternity } \\
\text { experienced less brood failure at the nestling stage than broods with single } \\
\text { paternity, and that females having experienced complete brood failure in } \\
\text { their previous breeding attempt had higher rates of mixed paternity than } \\
\text { either yearling or previously successful females. To better understand } \\
\text { these observations we also explored relationships between extra-pair } \\
\text { mating, male and female phenotype, and local breeding density. We found } \\
\text { that in almost all cases the sires of extra-pair offspring were close } \\
\text { neighbours, and that within those close neighbourhoods extra-pair sires } \\
\text { were older than other males not siring extra-pair offspring. Also, females } \\
\text { did not display consistent EPC status across years. Taken together our } \\
\text { results suggest that multiple mating might be a flexible female behaviour } \\
\text { influenced by previous breeding experience, and motivate further } \\
\text { experimental tests of causal links between extra-pair copulation and } \\
\text { predation. }\end{array}$ \\
\hline & \begin{tabular}{l}
$\mid l$ \\
\hline Abstract
\end{tabular} \\
\hline
\end{tabular}


1 Correlates of complete brood failure in blue tits: could extra-pair mating provide

$2 \quad$ unexplored benefits to females?

3

4 Running title: Extra-pair mating and brood failure in blue tits

5

6 Adèle Mennerat ${ }^{1,2 *}$, Anne Charmantier ${ }^{3,4}$, Christian Jørgensen ${ }^{1}$ and Sigrunn Eliassen ${ }^{1}$

7

$8{ }^{1}$ Department of Biological Sciences, University of Bergen, Postboks 7803, N-5020

9 Bergen, Norway

102 Ecologie et Dynamique des Systèmes Anthropisés, UMR 7058 CNRS-UPJV, 1 rue des

11 Louvels, 80037 Amiens Cedex 1, France

$12{ }^{3}$ Centre d'Ecologie Fonctionnelle et Evolutive, UMR 5175 Campus CNRS, 1919 Route

13 de Mende, 34293 Montpellier cedex 5, France

$14 \quad{ }^{4}$ Département des sciences biologiques, Université du Québec à Montréal, CP 888

15 Succursale centre-ville, Qc, Canada, H3P 3P8

16

$17 *$ corresponding author:

18 email: adele.mennerat@uib.no

19 Tel: +4755584214

20 Fax: +4755584450

21 


\section{Abstract}

23 Behavioural ecologists have for decades investigated the adaptive value of extra-

24 pair copulation (EPC) for females of socially monogamous species. Despite extensive

25 effort testing for genetic benefits, there now seems to be a consensus that the so-

26 called 'good genes' effects are at most weak. In parallel the search for direct benefits

27 has mostly focused on the period surrounding egg laying, thus neglecting potential

28 correlates of EPC that might be expressed at later stages in the breeding cycle. Here

29 we used Bayesian methods to analyse data collected over four years in a population

30 of blue tits (Cyanistes caeruleus), where no support was previously found for 'good

31 genes' effects. We found that broods with mixed paternity experienced less brood

32 failure at the nestling stage than broods with single paternity, and that females

33 having experienced complete brood failure in their previous breeding attempt had

34 higher rates of mixed paternity than either yearling or previously successful

35 females. To better understand these observations we also explored relationships

36 between extra-pair mating, male and female phenotype, and local breeding density.

37 We found that in almost all cases the sires of extra-pair offspring were close

38 neighbours, and that within those close neighbourhoods extra-pair sires were older

39 than other males not siring extra-pair offspring. Also, females did not display

40 consistent EPC status across years. Taken together our results suggest that multiple

41 mating might be a flexible female behaviour influenced by previous breeding

42 experience, and motivate further experimental tests of causal links between extra-

43 pair copulation and predation. 


\section{$45 \quad$ Keywords}

46 multiple mating, passerine bird, promiscuity

47

48 


\section{Introduction}

50 One way for a male of a socially monogamous species to increase his fitness is by

51 fertilizing extra-pair females, thus letting other males raise his extra-pair offspring

52 (Trivers 1972). Extra-pair copulation (EPC) and its outcome, extra-pair paternity

53 (EPP), are known to be widespread amongst socially monogamous birds (Griffith et

54 al. 2002). In such systems males are predicted to reduce their parental investment

55 when paternity in the nest is low or uncertain, and hence EPC is expected to

56 increase the reproductive burden for promiscuous females (Westneat and Sherman

57 1993, Kempenaers and Sheldon 1997, Arnqvist and Kirkpatrick 2005, Houston et al.

582005 , Schroeder et al. 2016). However, since EPC is a widespread strategy across

59 avian taxa, it has been suggested that benefits from EPC could be gained not only by

60 cuckolding males, but also by their female partners.

61 The observation that in many species females actively solicit extra-pair

62 copulations (Davies 1992, Kempenaers et al. 1992, Sheldon 1994a) further suggests

63 that EPCs might be (also) beneficial for females. Two main types of benefits for

64 females have been hypothesized, namely direct and indirect benefits. Tests of direct

65 benefits of EPC have mostly focused on precopulatory benefits (e.g. nuptial gifts) or

66 increased access to resources held by extra-pair males (e.g. Gray 1997), and have

67 been considered anecdotal in birds (Jennions and Petrie 2000, Griffith et al. 2002).

68 One other potential direct benefit of EPC is fertility insurance, whereby females

69 would maximise fertilisation success by obtaining extra-pair sperm to compensate

70 for infertility or sperm depletion of their social mates (Sheldon 1994b, Wedell et al. 
71 2002). Strikingly, direct benefits in terms of the contribution of extra-pair males to

72 post-hatching brood success have scarcely been investigated.

73 Indirect (genetic) benefits, on the other hand, have received much attention.

74 A main prediction is that if females seek EPC to increase the genetic 'quality' of their

75 offspring, then extra-pair offspring should have higher survival and/or reproductive

76 output than their within-pair half-siblings from the same nest. Although support for

77 such genetic benefits has been documented in some cases, the effect was found to be

78 weak at most (Akçay and Roughgarden 2007; but see Arct et al. 2015; Bowers et al.

79 2015), and a number of other studies found evidence of fitness costs - rather than

80 benefits - incurred by extra-pair offspring (Sardell et al. 2011, Hsu et al. 2014). All in

81 all, despite persistent interest, genetic benefits have received limited empirical

82 support. This has eventually led to an emerging consensus that although genetic

83 benefits may contribute through several weak mechanisms, they do not suffice to

84 explain the frequency and levels of EPP observed in natural populations (Arnqvist

85 and Kirkpatrick 2005, Charmantier and Sheldon 2006). It has also been suggested

86 that EPC in females may be better explained by non-adaptive mechanisms such as

87 genetic correlations between male and female behaviours, leading to indirect

88 selection on female promiscuity. However this is often not considered a satisfactory

89 general explanation for a phenomenon that is widespread both taxonomically and

90 across ecological settings (Arnold and Owens 2002; Griffith et al. 2002; reviewed in

91 Forstmeier et al. 2014).

$92 \quad$ Few studies of EPCs so far have explicitly considered that within-pair

93 offspring are not the only fitness component a male may influence through his 
94 behaviour. If males could, via some behavioural traits, contribute to the

95 reproductive success of their extra-pair females in addition to the parental

96 investment they provide at their own nests, these traits could be selected for

97 (Székely et al. 2013). One major cause of reproductive failure is brood failure, i.e. the

98 death of all nestlings. Despite the fact that brood failure can represent a potentially

99 strong selection pressure, it is underrepresented in behavioural studies of breeding

100 birds, mainly because observing or capturing breeding adults requires the presence

101 of live nestlings. This, combined with the strong focus on comparing within-pair to

102 extra-pair young in the search for indirect benefits, might explain why brood failure

103 has never been considered as a potential correlate of EPC.

104 There can be various causes for brood failure at the nestling stage, the

105 simplest being chick predation (Lima 2009). Predation on one of the parents can

106 also result in brood failure, because of the energetic challenge it represents for the

107 remaining parent to raise the brood alone. It is therefore not surprising that birds

108 display a wide range of antipredator strategies during breeding (Lima 2009). In

109 addition to alarm calls that may be perceived by neighbouring pairs as indicative of

110 the nearby presence of a predator, breeding adults can also join in collective

111 mobbing actions occurring in the neighbourhood (Caro 2005). In a number of small

112 passerine species, it was observed that the more individuals join the mob, the

113 sooner the predator tends to leave, and/or the longer it stays away (Hoogland and

114 Sherman 1976, Flasskamp 1994, Krams et al. 2010, Consla and Mumme 2012,

115 Grabowska-Zhang et al. 2012). Increasing the intensity of individual (e.g. alarm

116 calling) and collective (e.g. mobbing) antipredator behaviours might therefore be 
117 one mechanism through which males might enhance the post-hatching reproductive

118 success of neighbouring extra-pair females, without directly contributing to chick

119 provisioning (Eliassen and Jørgensen 2014, Sheldon and Mangel 2014).

120 Here we hypothesise that in such a case, broods having extra-pair sires in the

121 close neighbourhood would experience lower rates of post-hatching failure caused

122 by predation on chicks or on breeding adults. We explored this possibility in a

123 Mediterranean population of blue tits (Cyanistes caeruleus), where no clear evidence

124 was previously found for indirect (genetic) benefits of EPC (Charmantier and

125 Blondel 2003; Charmantier et al. 2004). In this population we identified events of

126 complete post-hatching brood failure that were directly or indirectly caused by

127 predation, and explored how their frequencies relate to mixed-paternity, as well as

128 to the proportion of extra-pair young (EPY) in the brood. We also assessed whether

129 individual females displayed repeatable EPP status across years, and whether

130 females having experienced brood failure displayed different levels of EPP

131 compared to previously successful females.

132 What we report here is an intriguing link between extra-pair mating and

133 both current and past brood failure. Given the results found, and in order to better

134 decipher what might explain them, we also tested for relationships between extra-

135 pair mating, male and female phenotype, and breeding density. More specifically, we

136 first explored the spatial range at which EPP was expressed, to better characterize

137 the pool of males that females may have chosen EP sires from. Within this spatial

138 range, we then tested whether EP sires differed from other potential mates in body

139 size, body weight, age, geographical distance or breeding synchrony, which may 
140 indicate whether certain male phenotypes were more likely to sire EP offspring.

141 Third, we tested whether females having EP offspring in their broods differed from

142 other females in body size, weight, age, laying date or clutch size. Finally, since

143 promiscuity may be affected by male availability (e.g. Charmantier and Perret

144 2004), we explored the links between two proxies of local breeding density and EPP.

\section{Materials and methods}

147 Study site and monitoring

148 We used data collected from 2000 to 2003 in a nestbox population of blue tits

149 located in the Rouvière oak woodland near Montpellier, Southern France $\left(43^{\circ} 40^{\prime} \mathrm{N}\right.$,

$150 \quad 03^{\circ} 40^{\prime}$ E, see Charmantier and Blondel 2003; Charmantier et al. 2004; Charmantier

151 and Perret 2004). Breeding events were monitored, and individuals were ringed

152 and measured using protocols described in e.g. Blondel et al. (2006). Blood samples

153 were collected from nestlings 5 to 9 days after hatching, and adults were captured

15410 to 15 days after hatching. There was no socially polygynous male in our sample.

155 Mixed paternity, i.e. the presence of EPY in broods was assessed in a total of 146

156 broods by comparing the genotypes of chicks (based on a set of seven microsatellite

157 markers, see Charmantier and Blondel 2003; Charmantier et al. 2004; Charmantier

158 and Perret 2004 for details) to that of the mother's social mate (i.e. the male

159 providing offspring care at her nest). There was no case of mismatch between

160 offspring and mother's genotype.

161

162 EPP rate and brood failure 
163 Field notebooks and databases were thoroughly checked to identify cases of post-

164 hatching brood failure (15 / 146), defined as death of all nestlings. No female in our

165 dataset experienced more than one such brood failure over the four years of the

166 study. Eight nests were not included in our sample because post-hatching failure

167 occurred either before the chicks were 5 days old (4 cases) or before the adults

168 could be captured ( 4 cases). We compared the frequencies of failure in mixed-

169 paternity vs single-paternity broods using a Bayesian generalized linear mixed-

170 effects model with brood failure as a binomial response variable, EPP status (i.e.

171 whether the brood had single or mixed paternity) and year as fixed effect factors,

172 and female identity (ID) as a random effect factor (MCMCgImm). We further

173 explored how the probability of brood failure related to the proportion of EPY in a

174 brood using a Bayesian generalized linear mixed-effects model with brood failure as

175 a binomial response variable, proportion of EPY and year as fixed effect factors, and

176 female ID as a random effect factor (MCMCgImm, see details below).

178 Previous breeding experience and current EPP

179 Focusing on those females that bred in two consecutive years over the four years of

180 the study ( $\mathrm{n}=81)$, we gathered information on EPP status $(n=42)$ and brood failure

181 ( $\mathrm{n}=81$ ) in the previous breeding season. Paternity, and hence EPP status could not

182 be assigned for all years and all broods because not all males could be captured in

183 all years. To explore whether EPP status was consistent across years we tested

184 whether those females that previously had mixed-paternity broods had higher rates

185 of EPP than those having had single-paternity broods. We used a Bayesian 
186 generalized linear mixed-effects model with current EPP status as a response

187 variable, previous EPP status as a fixed effect factor, and year as a random effect

188 factor (MCMCgImm, see details below).

189 We also compared the frequencies of mixed paternity in broods of females

190 having previously experienced brood failure to those of previously successful

191 females. We used a Bayesian generalized linear mixed-effects model (MCMCglmm)

192 with EPP status as a response variable, previous breeding experience (failure or

193 success) as a fixed effect factor, and year as a random effect factor. Similarly we

194 compared EPP status between yearling females (i.e. reproductively naive) and

195 previously successful females.

197 Mapping neighbourhoods

198 Based on the GPS coordinates of nestboxes, and using Dirichlet tessellation, we

199 estimated territories as Thiessen polygons around each active nest box, as these

200 were shown to appropriately represent territory size in paridae (e.g. Wilkin et al.

201 2006). For territories at the edge of the study area, the outer border was defined so

202 that the nest was located at the centre of the territory. The edges of the study area

203 did not correspond to the edges of the forest (as only a portion of the forest was

204 equipped with nest boxes), and there was no obvious difference in EPP between

205 edge ( $n=63$ nests, 46\% EPP) and central ( $n=90$ nests, 48\% EPP) territories.

206 Excluding data from all edge nests would have resulted in a significant reduction of

207 our sample, and we therefore decided to include all territories in our sample. 
208 From the maps obtained for each study year, we then assigned the territories 209 surrounding each nest to one of four groups representing first, second, third, and 4+

210 order neighbours. First order neighbours are those nests sharing one territory

211 border with the focal brood; second (resp. third) order neighbours shared border

212 with the first (resp. second) order neighbours, and 4+ order neighbours consisted of

213 the remaining territories in the population. Broods with a hatching date posterior to

214 the date when the earliest brood in the population had fledged were excluded from

215 our analysis, so that our sample only consisted of nests with overlapping periods of 216 activity.

218 Spatial range of EPP

219 Across 146 broods, 69 (i.e. 47\%) were identified as mixed-paternity broods. Among 220 the 47 broods where paternity could be assigned to a known breeding male, 33 had 221 at least one EPY sired by first-order male neighbours. A remaining number of 10, 3,

222 and 1 broods had at least one EPY sired by second-, third-, and 4+-order male

223 neighbours, respectively (Figure 1). Consistent with earlier findings in this

224 population (Charmantier and Perret 2004), this indicates that EP sires are mainly

225 chosen from the close neighbourhood. For the rest of this study, we therefore

226 focused on first-order neighbourhoods as representing the main pool of potential EP 227 sires that females may have chosen from.

228

229 EP sires vs other first-order male neighbours 
230 We tested whether EP sires and other first-order male neighbours differed in terms

231 of male body size, weight, age, breeding asynchrony, and breeding distance to the

232 focal brood. The difference in egg-laying dates was used as a measure of breeding

233 asynchrony. Geographical distances were calculated from the GPS coordinates of

234 nest boxes. Tarsus length, measured to the nearest $0.1 \mathrm{~mm}$ with a calliper, was used

235 as a proxy for male body size. Body weight was measured to the nearest $0.1 \mathrm{~g}$ with a

236 Pesola spring scale. Male age (in years) was determined from plumage coloration at

237 first capture and from previous ring-marking records. We used minimum age at

238 capture for those birds that were first caught as adults. We randomly selected one

239 record for those individuals that were recorded in more than one year. To compare

240 EP sires with other first-order neighbours we used Bayesian estimation, as this

241 method is more powerful than classical t-tests (Kruschke 2013), via the online

242 version of “BEST" for two-sample comparisons (Bååth 2012, see details below). 243

$244 \quad$ Females with mixed-paternity broods vs. other females

245 We tested whether females with mixed-paternity broods differed from other

246 females in body size, weight, age, laying date, or clutch size. Female body size,

247 weight, and age were measured as described for males, and laying date was defined

248 as the date when the first egg in a clutch was laid. We randomly selected one record

249 for those individuals that were recorded in more than one year. Comparisons were

250 carried out using Bayesian estimation (BEST, Bååth 2012, see details below).

252 EPP rate and local breeding density 
253 Two different proxies for density were used, namely the number of first-order

254 neighbours (ranging from 2 to 9) and the mean distance to first-order neighbours

255 (ranging from $57.1 \mathrm{~m}$ to $238 \mathrm{~m}$ ). To explore whether density might be related to

256 EPP, we compared these two proxies between mixed-paternity and single-paternity

257 broods using Bayesian estimation as above (BEST, Bååth 2012, see details below).

258 For each study year we also tested for spatial autocorrelation in EPP occurrence,

259 which might indicate clustering in EPP events, using Moran's I (ape library, R 3.2.3,

260 R Core Team 2015). Since Moran's I was never significant (see results) further

261 analyses were performed assuming no spatial autocorrelation.

262 For all two-sample comparisons using BEST the burn-in period was 20000

263 and the number of iterations 200000 (Bååth 2012). For all Bayesian estimation

264 analyses using MCMCgImm (MCMCgImm library in R 3.2.3, R Core Team 2015),

265 family was defined as "categorical" and residual variance at the limit was set to 1.

266 The random effect variance structure $(G)$ used in the prior included a variance set to

2671 and a degree of belief (nu) set to 0.002 . The number of iterations and thinning

268 interval were defined so that the effective sample size was 1000 or more, while

269 keeping autocorrelation between successive samples below 0.1 (Hadfield 2017). For

270 almost all models the thinning interval was 200 and the number of iterations

271300000 (except for the model with proportion of EPY as dependent variable, for

272 which the thinning interval was 200 and the number of iterations 600000).

273 Convergence of the models was assessed by visual inspection of traces.

\section{Results}


277 Mixed-paternity broods experienced complete brood failures less frequently than

278 single-paternity broods (mixed: 3/69; single: 12/77; MCMCglmm: $P=0.02$; Table

279 1A). In addition, brood failure occurrence decreased with increasing proportions of 280 EPY (MCMCglmm: $P=0.01$; Table 1B).

\section{Previous breeding experience and current EPP}

283 The probability of mixed paternity in a current year did not differ between females

284 that previously had mixed-paternity broods $(10 / 22)$ and those that previously had 285 single-paternity broods (12/19) (MCMCglmm: $\mathrm{P}=0.17$; Table 2), suggesting low 286 repeatability of mixed paternity for females. However, females having previously 287 experienced complete brood failures had mixed-paternity broods more often $(9 / 11)$ 288 than previously successful females (32/70) (MCMCgImm: $\mathrm{P}=0.02$; Table 2), while 289 the latter did not differ in EPP status from inexperienced (yearling) females (29/63) 290 (MCMCglmm: $\mathrm{P}=0.97$; Table 2; Figure 2).

292 EP sires vs. other first-order male neighbours

293 Within first-order neighbourhoods of mixed-paternity broods, there was no

294 difference between EP sires $(n=24)$ and other males $(n=60)$ in body size, weight, 295 breeding asynchrony, or geographical distance (all 95\% highest-density intervals 296 included zero, Table 3A). EP sires were, however, older than other first-order male 297 neighbours (BEST; Table 3A). 
299 Females with mixed-paternity broods vs. other females

300 Females with mixed-paternity broods $(n=45)$ did not differ from other females

301 ( $n=57)$ in body size, weight, age, laying date or clutch size (all 95\% highest density

302 intervals included zero; BEST; Table 3B).

303

304 EPP rate and local breeding density

305 Neither the number of first-order neighbours, nor the mean distance to first-order

306 neighbours, differed between mixed-paternity and single-paternity broods (BEST,

307 Table 4). In addition, in none of the study years was there any statistically

308 significant spatial autocorrelation in EPP occurrence (Moran's I; year 2000, $P=0.83$;

$3092001, P=0.49 ; 2002, P=0.48 ; 2003, P=0.87)$.

310

\section{Discussion}

312 In this study we found a combination of patterns that, taken together, cannot be

313 fully explained by current hypotheses of the benefits of EPC for females. We indeed

314 found reduced brood failure in mixed-paternity broods compared to broods sired by

315 a single male, and a negative relation between brood failure and the proportion of

316 EPY in broods. Furthermore, in the same population no difference in age,

317 morphometrics, or condition was previously found between cuckolded and non-

318 cuckolded males, nor between cuckolded and cuckolding males, and no difference in

319 survival or recruitment was revealed between WP and EP offspring (Charmantier et

320 al. 2004). The 'good genes' hypothesis therefore does not seem supported in this

321 population, and more importantly, 'good genes' effects could not explain why all 
322 nestlings in a brood would survive better, regardless of the genes they may carry,

323 when the brood is sired by more than one male. Finally, given the common

324 expectation that cuckolded males should provide less care and protection for their

325 brood due to low paternity (but see Schroeder et al. 2016), our observations require

326 alternative explanations.

327 A first tentative explanation for the difference in brood failure between

328 brood types is that areas differed in both resource availability and extra-pair

329 mating, with extra-pair mating higher in areas of high food abundance or low

330 predation risk. Yet, while spatial autocorrelation in habitat types (Szulkin et al.

3312015 ) and in fitness (Marrot et al. 2015) are present in this population, our dataset

332 revealed no spatial autocorrelation in EPP occurrence or brood failure, and no effect

333 of breeding density on EPP status within first-order neighbourhoods, suggesting

334 that extra-pair mating occurred independently of local habitat quality (but see

335 Charmantier and Perret 2004 for effects at larger spatial scales). Second, we

336 hypothesized that variation in behaviour or other characteristics of males or

337 females could influence both EPP occurrence and failure rate. For example, if

338 multiply mating females had higher body condition, longer breeding experience, or

339 specific behavioural types, this could translate into higher brood success (van Oers

340 et al. 2004, Patrick et al. 2012). While we did not find any difference in age, body

341 size, body condition, or breeding phenology between mothers of mixed-paternity

342 broods and those of single-paternity broods, we did however not directly measure

343 their behaviour, and cannot rule out that they might have differed in some other

344 traits. This might also apply to males, and in particular the link between male 
345 propensity to loose paternity and the level of protection and care received by their

346 brood (e.g. Patrick et al. 2012; Schroeder et al. 2016), is an aspect that would

347 require further investigation.

$348 \quad$ However, differences in behavioural traits alone would not suffice to explain

349 why older male neighbours would sire more EP offspring, irrespective of other

350 phenotypic traits. One potential explanation is that in case of selective

351 disappearance (Bouwhuis et al. 2009), male age might reflect male genetic quality,

352 with older males being those better able to survive, and hence that EPP would be

353 driven by a combination of personality and good genes effects. In the absence of any

354 differences in survival or recruitment rate between WP and EP offspring

355 (Charmantier et al. 2004), however, this explanation appears unlikely.

356 Even though our results remain correlative, they tend to suggest that

357 females, by engaging in EPC with their close neighbours, would gain some protective

358 advantage to their brood. Older males are potentially also those with the longest

359 local breeding experience, and hence may be better able to warn the neighbourhood

360 against predators or interact with neighbours in other beneficial ways. We also

361 found that previous experience of complete, post-hatching brood failure by females

362 was associated with a higher frequency of EPP, as compared to either

363 unexperienced or previously successful females. This suggests that EPC may be a

364 flexible female behaviour. Taken together our results suggest that EPP may confer a

365 direct benefit in terms of decreased brood failure, perhaps via increased vigilance,

366 mobbing, or other behaviours through which neighbouring adults may contribute

367 even though they do not participate in chick provisioning. 
When breeding pairs, and particularly yearling individuals, settle in a

369 territory there might be insufficient environmental cues available to accurately

370 assess risk of future failure. If this risk is perceived during the fertile period, it

371 follows from our reasoning that one way for females to respond would be by

372 seeking more EPC. If the risk of failure is perceived after the end of the fertile period,

373 such an immediate response becomes impossible, and females could benefit not

374 only from moving to a safer site (e.g. Danchin et al. 1998, Doligez et al. 2004), but

375 also from altering their mating strategy in their next breeding attempt (Lima 2009).

376 Experimental tests would be needed to establish a causal link between perceived

377 risk of failure and EPP rate, and we are currently exploring this further. If true, this

378 hypothesis might help explain why EPP seems to have low repeatability for females,

379 not only in our study population, but also in other species (I. Winney, pers. comm.;

380 Reid et al. 2011).

381 In our study population, the main predators on blue tit chicks are mustelids

382 like the weasel Mustela nivalis and the common genet Genetta genetta (that learned

383 to open Schwegler nestboxes from the front), while the main predator on adults is

384 the Eurasian sparrowhawk Accipiter nisus. Brood failures resulted either from brood

385 predation, i.e. disappearance of all nestlings from a nest box prior to day 15 (five

386 cases), or corresponded to cases when one breeding adult disappeared shortly after

387 having been observed feeding a brood with nestlings in good condition, and was

388 never recorded again (i.e. in the 12 years following the end of the present study). We

389 could infer that an individual was missing when it was previously caught and ringed

390 (between 11 and 14 days post-hatching), but not observed again when the chicks 
391 were measured at day 15 post-hatching (the presence and number of adults

392 alarming was systematically noted). Even though we cannot provide definitive

393 evidence, for such cases we assume that death by predation is the most likely cause

394 of disappearance (10 cases). This assumption seems supported by recent

395 observations in another population of blue tits, where almost all cases of complete

396 brood failure were related to sudden and permanent disappearance of one of the

397 parents; in those cases the missing parent was recorded (via automated

398 monitoring) active at the nest up to the point where it disappeared, which points to

399 predation as the most likely cause of disappearance (Santema and Kempenaers,

400 unpublished results). But even assuming that nest desertion might explain some of

401 the failing broods, our observations contradict the common assumption that males

402 should be more prone to desertion of those broods where paternity is shared

403 (Trivers 1972, Houston and McNamara 2002). Here we observe the opposite, i.e.

404 that broods with single paternity are more prone to failure. In addition, as far as we

405 can observe in our sample, EPP rate was not linked to pair-bond stability, as the

406 frequency of mixed paternity did not vary between pairs that divorced and both

407 individuals bred again separately (19 cases, 42\% EPP), and those that remained

408 stable (18 cases, 44\% EPP). Noticeably, and irrespective of brood failure, EPP rate

409 was found higher in cases where the previous male partner was never found again

410 (33 cases, 61\% EPP). Finally, we did not find any relation between EPP and two

411 measures of local breeding density, which tends to contradict the assumption that

412 EPC might simply emerge from high local availability of mating partners. Our

413 hypothesis, i.e. that broods sired by multiple males would gain overall better success 
414 through post-copulatory mechanisms, therefore appears as the most parsimonious

415 explanation given the set of patterns of EPP and complete brood failure (likely due

416 to predation) in this population.

417 Identification of individuals in traditionally monitored passerine populations

418 usually requires the recapture of ring-marked birds, which may lead to sampling

419 bias because some individuals (e.g. early-failing breeders) have very low detection

420 probabilities (Kidd et al. 2015). Fortunately, an increasing number of bird

421 populations are now equipped with devices allowing automated or remote

422 detection of individuals (e.g. Aplin et al. 2012; Farine et al. 2015), and this will make

423 it easier to study brood failure and extra-pair behaviour of males and females. For

424 example, a recent study using passive integrative transponder (PIT) tags showed

425 that both male and female blue tits made frequent forays in the territories of their

426 first-order neigbhours throughout the breeding season, which suggests that close

427 neighbours interact in a number of ways that yet remain to be investigated (Schlicht 428 et al. 2015).

429 A fundamental limitation of our study is the correlative nature of the results.

430 We do not claim to be providing definitive support for a causal link between EPP

431 and predation, yet the intriguing observations reported here are consistent with it

432 when taken together, while they cannot be fully explained by current alternative

433 hypotheses. Similar evidence from other populations as well as field experiments

434 such as manipulations of predator risk assessment are now required. This study

435 illustrates the idea that focusing on brood failure might yield overlooked insights, 
436 and that all possible ecological benefits of EPC might not have been fully explored 437 yet.

\section{Acknowledgements}

440 We thank Philippe Perret, Jacques Blondel and Marcel Lambrechts for assistance on 441 the field, as well as all other students, postdocs and fieldworkers who collected data

442 in the Rouvière study site in 2000-2003. Thanks to Göran Högstedt, Adriana

443 Maldonado Chaparro, and Kristina Beck for providing feedback on earlier drafts of

444 this manuscript. We are also grateful for constructive comments from two

445 anonymous referees. AC was funded by the European Research Council (Starting

446 grant ERC-2013-StG-337365-SHE to AC) and the OSU OREME. SE, CJ and AM were

447 funded by the Research Council of Norway (grant 222021/F20). All applicable

448 national guidelines for the care and use of animals were followed, and all

449 procedures performed were in accordance with the ethical standards of the

450 institution at which the studies were conducted.

\section{$452 \quad$ References}

453 Akçay, E. and Roughgarden, J. 2007. Extra-pair paternity in birds: Review of the genetic benefits. - Evol. Ecol. Res. 9: 855-868.

455 Aplin, L. M., Farine, D. R., Morand-Ferron, J. and Sheldon, B. C. 2012. Social networks predict patch discovery in a wild population of songbirds. - Proc. R. Soc. B Biol. Sci. 279: 4199-4205.

Arct, A., Drobniak, S. M. and Cichoń, M. 2015. Genetic similarity between mates predicts extrapair paternity-a meta-analysis of bird studies. - Behav. Ecol. 26: 959-968.

Arnold, K. E. and Owens, I. P. F. 2002. Extra-pair paternity and egg dumping in birds: life history, parental care and the risk of retaliation. - Proc. R. Soc. B Biol. Sci. 269: 1263-1269.

Arnqvist, G. and Kirkpatrick, M. 2005. The evolution of infidelity in socially 
monogamous passerines: the strength of direct and indirect selection on extrapair copulation behavior in females. - Am. Nat. 165 Suppl: S26-S37.

Bååth, R. 2012. Bayesian estimation Supersedes the t-test (BEST) - online. http://www.sumsar.net/best_online/

Blondel, J., Thomas, D. W., Charmantier, A., Perret, P., Bourgault, P. and Lambrechts, M. M. 2006. A Thirty-Year Study of Phenotypic and Genetic Variation of Blue Tits in Mediterranean Habitat Mosaics. - Bioscience 56: 661.

Bouwhuis, S., Sheldon, B. C., Verhulst, S. and Charmantier, A. 2009. Great tits growing old: selective disappearance and the partitioning of senescence to stages within the breeding cycle. - Proc. Biol. Sci. 276: 2769-77.

Bowers, E. K., Forsman, A. M., Masters, B. S., Johnson, B. G. P., Johnson, L. S., Sakaluk, S. K. and Thompson, C. F. 2015. Increased extra-pair paternity in broods of aging males and enhanced recruitment of extra-pair young in a migratory bird. - Evolution (N. Y). 69: 2533-2541.

Caro, T. 2005. Antipredator defenses in birds and mammals. - University of Chicago Press.

Charmantier, A. and Blondel, J. 2003. A Contrast in Extra-Pair Paternity Levels on Mainland and Island Populations of Mediterranean Blue Tits. - Ethology 109: 351-363.

Charmantier, A. and Perret, P. 2004. Manipulation of nest-box density affects extrapair paternity in a population of blue tits (Parus caeruleus). - Behav. Ecol. Sociobiol. 56: 360-365.

Charmantier, A. and Sheldon, B. C. 2006. Testing genetic models of mate choice evolution in the wild. - Trends Ecol. Evol. 21: 417-9.

Charmantier, A., Blondel, J., Perret, P. and Lambrechts, M. M. 2004. Do extra-pair paternities provide genetic benefits for female blue tits Parus caeruleus ? - J. Avian Biol. 35: 524-532.

Consla, D. J. and Mumme, R. L. 2012. Response of Captive Raptors to Avian Mobbing Calls: the Roles of Mobber Size and Raptor Experience. - Ethology 118: 10631071.

Danchin, E., Boulinier, T. and Massot, M. 1998. Conspecific Reproductive Success and Breeding Habitat Selection : Implications for the Study of Coloniality. - Ecology 79: 2415-2428.

Davies, N. B. 1992. Dunnock behaviour and social evolution. - Oxford University Press.

Doligez, B., Pärt, T. and Danchin, E. 2004. Prospecting in the collared flycatcher: Gathering public information for future breeding habitat selection? - Anim. Behav. 67: 457-466.

Eliassen, S. and Jørgensen, C. 2014. Promiscuity and evolution of cooperative neighbourhoods. - PLoS One 9: e99878.

Farine, D. R., Aplin, L. M., Sheldon, B. C. and Hoppitt, W. 2015. Interspecific social networks promote information transmission in wild songbirds. - Proc. Biol. Sci. 282: 20142804.

Flasskamp, A. 1994. The Adaptive Significance of Avian Mobbing V. An Experimental Test of the "Move On" Hypothesis. - Ethology 96: 322-333.

Forstmeier, W., Nakagawa, S., Griffith, S. C. and Kempenaers, B. 2014. Female extra- 
511

512

513

514

515

516

517

518

519

520

521

522

523

524

525

526

527

528

529

530

531

532

533

534

535

536

537

538

539

540

541

542

543

544

545

546

547

548

549

550

551

552

553

554

555

556 pair mating: adaptation or genetic constraint? - Trends Ecol. Evol. 29: 456-64. Grabowska-Zhang, A. M., Sheldon, B. C. and Hinde, C. A. 2012. Long-term familiarity promotes joining in neighbour nest defence. - Biol. Lett. 8: 544-6.

Gray, E. 1997. Female red-winged blackbirds accrue material benefits from copulating with extra-pair males. - Anim. Behav.: 625-639.

Griffith, S. C., Owens, I. P. F. and Thuman, K. A. 2002. Extra pair paternity in birds: A review of interspecific variation and adaptive function. - Mol. Ecol. 11: 21952212.

Hadfield, J. 2017. MCMCglmm course notes. See http://cran. r-project. org/web/packages/MCMCglmm/vignettes/CourseNotes.pdf. in press.

Hoogland, J. L. and Sherman, P. W. 1976. Advantage and disadvantages of bank swallow (Riparia riparia) coloniality. - Ecol. Monogr. 46: 33-58.

Houston, A. I. and McNamara, J. M. 2002. A self-consistent approach to paternity and parental effort. - Philos. Trans. R. Soc. London B Biol. Sci.: 351-362.

Houston, A., Székely, T. and McNamara, J. M. 2005. Conflict between parents over care. - Trends Ecol. Evol. 20: 33-38.

Hsu, Y. H., Schroeder, J., Winney, I., Burke, T. and Nakagawa, S. 2014. Costly infidelity: Low lifetime fitness of extra-pair offspring in a passerine bird. Evolution (N. Y). 68: 2873-2884.

Jennions, M. D. and Petrie, M. 2000. Why do females mate multiply? A review of the genetic benefits. - Biol. Rev. Camb. Philos. Soc. 75: 21-64.

Kempenaers, B. and Sheldon, B. C. 1997. Studying paternity and paternal care: pitfalls and problems.: 423-427.

Kempenaers, B., Verheyen, G. R., Van den Broeck, M., Burke, T., Van Broeckhoven, C. and Dhondt, A. A. 1992. Extra-pair paternity results from female preference for high-quality males in the blue tit. - Nature 357: 494-496.

Kidd, L. R., Sheldon, B. C., Simmonds, E. G. and Cole, E. F. 2015. Who escapes detection? Quantifying the causes and consequences of sampling biases in a long-term field study. - J. Anim. Ecol. 84: 1520-1529.

Krams, I., Bërziņš, A., Igaune, K. and Rantala, M. J. 2010. The increased risk of predation enhances cooperation. 277: 513-518.

Kruschke, J. K. 2013. Bayesian Estimation Supersedes the t Test. - J. Exp. Psychol. Gen. 142: 573-603.

Lima, S. L. 2009. Predators and the breeding bird: Behavioral and reproductive flexibility under the risk of predation. - Biol. Rev. 84: 485-513.

Marrot, P., Garant, D. and Charmantier, A. 2015. Spatial autocorrelation in fitness affects the estimation of natural selection in the wild. - Methods Ecol. Evol. 6: 1474-1483.

Patrick, S. C., Chapman, J. R., Dugdale, H. L., Quinn, J. L. and Sheldon, B. C. 2012. Promiscuity, paternity and personality in the great tit. - Proc. Biol. Sci. 279: 1724-30.

R Core Team 2015. R: A language and environment for statistical computing. R Foundation for Statistical Computing, Vienna, Austria. in press.

Reid, J. M., Arcese, P., Sardell, R. J. and Keller, L. F. 2011. Heritability of female extrapair paternity rate in song sparrows (Melospiza melodia). - Proc. Biol. Sci. 278: 1114-20. 
557 Sardell, R. J., Arcese, P., Keller, L. F. and Reid, J. M. 2011. Sex-specific differential 558 survival of extra-pair and within-pair offspring in song sparrows, Melospiza melodia. - Proc. R. Soc. B Biol. Sci. 278: 3251-3259.

Schlicht, L., Valcu, M. and Kempenaers, B. 2015. Male extraterritorial behavior predicts extrapair paternity pattern in blue tits, Cyanistes caeruleus. - Behav. Ecol. 26: 1404-1413.

Schroeder, J., Hsu, Y.-H., Winney, I., Simons, M. J. P., Nakagawa, S. and Burke, T. 2016. Predictably philandering females prompt poor paternal provisioning. - Am. Nat. online ear: 000-000.

Sheldon, B. C. 1994a. Sperm competition in the chaffinch: the role of the female. Anim. Behav. 47: 163-173.

Sheldon, B. C. 1994b. Male Phenotype, Fertility, and the Pursuit of Extra-Pair Copulations by Female Birds. - Proc. R. Soc. B Biol. Sci. 257: 25-30.

Sheldon, B. C. and Mangel, M. 2014. Love thy neighbour. 512: 381-382.

Székely, T., Remeš, V., Freckleton, R. P. and Liker, A. 2013. Why care? Inferring the evolution of complex social behaviour. - J. Evol. Biol. 26: 1381-1391.

Szulkin, M., Zelazowski, P., Marrot, P. and Charmantier, A. 2015. Application of high resolution satellite imagery to characterize individual-based environmental heterogeneity in a wild blue tit population. - Remote Sens. 7: 13319-13336.

Trivers, R. L. 1972. Parental investment and sexual selection. - In: Campbell, B. (ed), Sexual selection and the Descent of Man, 1871-1971. Aldine-Atherton, in press.

van Oers, K., Drent, P. J., de Goede, P. and van Noordwijk, A. J. 2004. Realized heritability and repeatability of risk-taking behaviour in relation to avian personalities. - Proc. Biol. Sci. 271: 65-73.

Wedell, N., Gage, M. J. G. and Parker, G. A. 2002. Sperm competition, male prudence, and sperm-limited females. - Trends Ecol. Evol. 17: 313-320.

Westneat, D. F. and Sherman, P. W. 1993. Parentage and the evolution of paternal care. - Behav. Ecol. 4: 66-77.

Wilkin, T. A., Garant, D., Gosler, A. G. and Sheldon, B. C. 2006. Density effects on lifehistory traits in a wild population of the great tit Parus major: Analyses of longterm data with GIS techniques. - J. Anim. Ecol. 75: 604-615. 
590 Figure 1. Distribution of the spatial distances between EP offspring and the

591 corresponding EP sires (see Methods for a definition of the four distance classes).

592

593 Figure 2. Mixed paternity in relation to the experience of females (success or failure

594 of their previous brood). Yearling females have no reproductive experience. The

595 number of broods in each group is indicated, and letters indicate credible

596 differences between the groups (MCMCglmm, see Methods).

597 
598 Figure 1

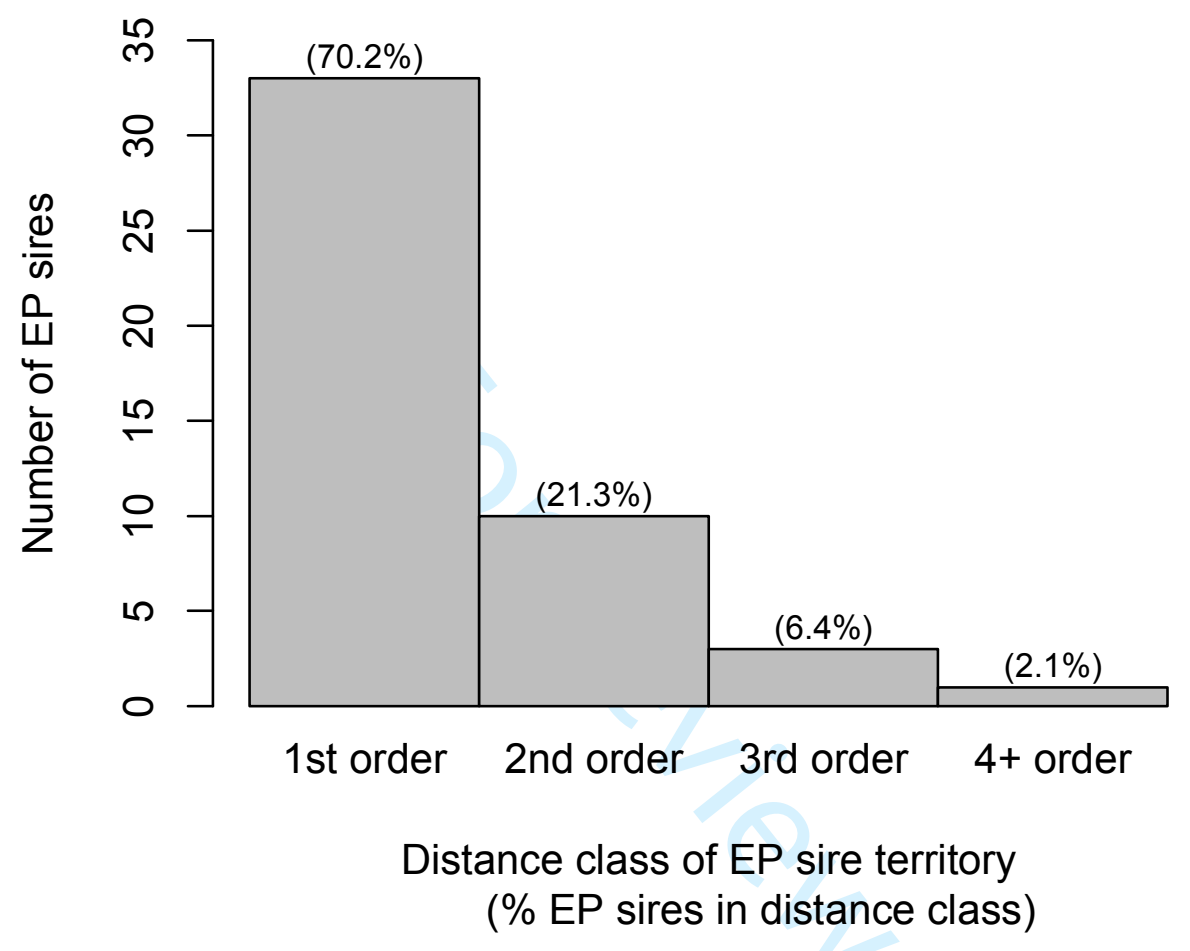

599

600

601 
602 Figure 2

603

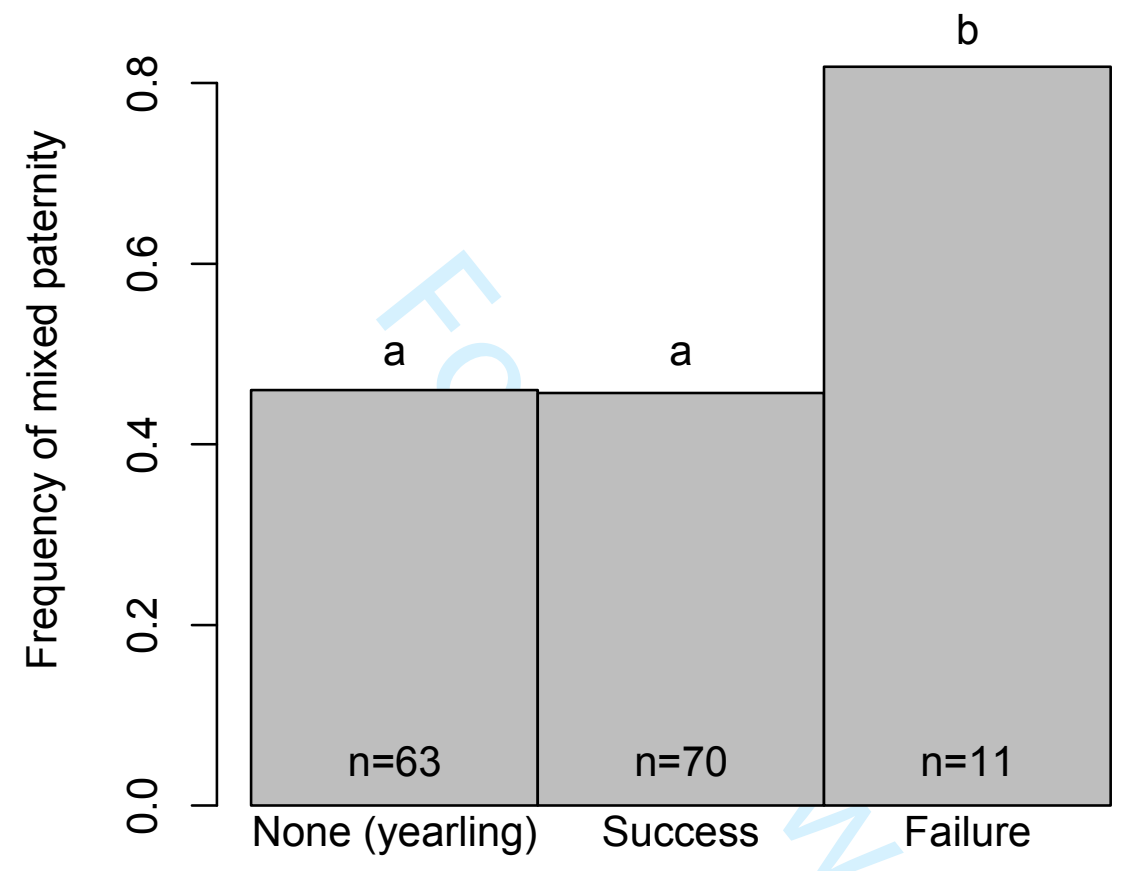

Outcome of previous brood

604

605 


\begin{tabular}{|c|c|c|c|c|c|}
\hline & $\begin{array}{l}\text { Posterior } \\
\text { mean }\end{array}$ & $\begin{array}{l}\text { Lower 95\% } \\
\text { CI }\end{array}$ & $\begin{array}{l}\text { Upper 95\% } \\
\text { CI }\end{array}$ & $\begin{array}{l}\text { Effective sample } \\
\text { size }\end{array}$ & $\mathrm{P}$ \\
\hline \multicolumn{6}{|c|}{ A. EPP status } \\
\hline EPP status & -1.57 & -3.08 & -0.19 & 1334 & 0.018 \\
\hline Year & -0.57 & -1.13 & -0.02 & 1368 & 0.051 \\
\hline \multicolumn{6}{|c|}{ B. Proportion EPY } \\
\hline $\begin{array}{l}\text { Proportion } \\
\text { of EPY }\end{array}$ & -6.98 & -13.85 & -0.68 & 1150 & 0.012 \\
\hline Year & -0.57 & -1.16 & 0.04 & 2985 & 0.054 \\
\hline
\end{tabular}

606

607 Table 1. Results of Bayesian generalized linear mixed-effects models (MCMCgImm )

608 explaining the probability of complete post-hatching brood failure in relation to

609 either (A) the EPP status of broods (mixed vs single paternity) or (B) the proportion

610 of EPY in broods. See Methods.

611 


\begin{tabular}{|l|l|l|l|l|l|}
\hline & Posterior & Lower 95\% & Upper 95\% & Effective sample & P \\
& mean & CI & CI & size & \\
\hline A. Past EPP & -1.17 & -2.86 & 0.58 & 1485 & 0.174 \\
\hline $\begin{array}{l}\text { B. Past } \\
\text { failure }\end{array}$ & 2.16 & 0.17 & 4.24 & 1115 & 0.019 \\
\hline $\begin{array}{l}\text { C. } \\
\text { Experience }\end{array}$ & -0.004 & -0.78 & 0.92 & 1485 & 0.974 \\
\hline
\end{tabular}

612

613 Table 2. Results of Bayesian generalized linear mixed-effects models (MCMCgImm,

614 see Methods) explaining the probability of mixed paternity in broods of a current

615 year in relation to (A) the EPP status of the same female's brood the previous year,

616 (B) brood outcome in the previous year (fledging vs complete post-hatching brood

617 failure), or (C) breeding experience of the female (either yearling or having

618 previously fledged a brood).

619

620

621 


\begin{tabular}{|c|c|c|c|c|}
\hline \multirow{3}{*}{\begin{tabular}{|l} 
\\
A. Males \\
\end{tabular}} & \multicolumn{2}{|c|}{ Mean \pm SD } & \multicolumn{2}{|c|}{ 95\% HDI } \\
\hline & & & Min & $\operatorname{Max}$ \\
\hline & $\begin{array}{l}\text { EP sires } \\
(n=24)\end{array}$ & $\begin{array}{l}\text { Other males } \\
(\mathrm{n}=60)\end{array}$ & & \\
\hline Tarsus length (mm) & $16.86 \pm 0.39$ & $16.90 \pm 0.41$ & -0.15 & 0.25 \\
\hline Body weight (g) & $10.82 \pm 0.43$ & $11.10 \pm 0.53$ & -0.01 & 0.46 \\
\hline Age (y) & $2.21 \pm 0.98$ & $1.93 \pm 1.40$ & $\begin{array}{l}-1.52 \\
\end{array}$ & -0.73 \\
\hline Breeding synchrony $(\mathrm{d})$ & $0.38 \pm 7.96$ & $1.93 \pm 8.20$ & -2.24 & 5.54 \\
\hline Distance to brood (m) & $133.64 \pm 74.19$ & $107.67 \pm 43.38$ & -58.1 & 9.99 \\
\hline B. Females & $\begin{array}{l}\text { With EPY } \\
(n=45)\end{array}$ & $\begin{array}{l}\text { Without EPY } \\
(n=57)\end{array}$ & & \\
\hline Tarsus length (mm) & $16.43 \pm 0.42$ & $16.49 \pm 0.55$ & -0.26 & 0.13 \\
\hline Body weight (g) & $11.04 \pm 0.48$ & $10.92 \pm 0.60$ & -0.10 & 0.34 \\
\hline Age (y) & $1.76 \pm 1.05$ & $1.61 \pm 0.82$ & -0.26 & 0.49 \\
\hline Laying date $(\mathrm{d})$ & $35.51 \pm 5.43$ & $34.86 \pm 5.76$ & -2.03 & 3.37 \\
\hline Clutch size & $9.71 \pm 1.68$ & $9.77 \pm 1.50$ & $\begin{array}{l}-0.71 \\
\end{array}$ & 0.55 \\
\hline
\end{tabular}

624

625 Table 3. Comparison of EP sires with other first-order male neighbours of mixed-

626 paternity broods (A), and of females with and without EPY (B). The 95\% highest

627 density interval (HDI) represents the credible interval of the difference in means 
628 between the groups. EP sires were older than other first order, male neighbours of

629 mixed-paternity broods. There was no credible difference in any of the other male 630 or female variables, since all other 95\% HDIs included zero (BEST, see Methods).

631 


\begin{tabular}{|l|l|l|l|l|}
\hline \multirow{2}{*}{} & \multicolumn{2}{|c|}{ Mean \pm SD } & \multicolumn{2}{c|}{$95 \%$ HDI } \\
\cline { 2 - 5 } & With EPP (n=69) & No EPP & Min & Max \\
& & $n=77)$ & & \\
\hline Number of neighbours & $4.63 \pm 1.58$ & $4.76 \pm 1.34$ & -0.34 & 0.63 \\
\hline Mean distance to neighbours (m) & $114.03 \pm 38.34$ & $107.00 \pm$ & -19.6 & 5.43 \\
& & 39.01 & & \\
\hline
\end{tabular}

632

633 Table 4. Breeding density (as represented by two different proxies) in first-order

634 neighbourhoods of mixed-paternity (with EPP) and single-paternity broods (no

635 EPP). The 95\% highest density interval (HDI) represents the credible interval of the

636 difference in means between the groups. Both 95\% HDIs included zero, which

637 means that there was no credible difference in breeding density (BEST, see

638 Methods).

639 
1 Correlates of complete brood failure in blue tits: could extra-pair mating provide

$2 \quad$ unexplored benefits to females?

4 Running title: Extra-pair mating and brood failure in blue tits

6 Adèle Mennerat ${ }^{1,2 *}$, Anne Charmantier ${ }^{3,4}$, Christian Jørgensen ${ }^{1}$ and Sigrunn Eliassen ${ }^{1}$ 7

$8{ }^{1}$ Department of Biological Sciences, University of Bergen, Postboks 7803, N-5020

9 Bergen, Norway

102 Ecologie et Dynamique des Systèmes Anthropisés, UMR 7058 CNRS-UPJV, 1 rue des

11 Louvels, 80037 Amiens Cedex 1, France

$12{ }^{3}$ Centre d'Ecologie Fonctionnelle et Evolutive, UMR 5175 Campus CNRS, 1919 Route

13 de Mende, 34293 Montpellier cedex 5, France

$14 \quad{ }^{4}$ Département des sciences biologiques, Université du Québec à Montréal, CP 888

15 Succursale centre-ville, Qc, Canada, H3P 3P8

16

$17 *$ corresponding author:

18 email: adele.mennerat@uib.no

19 Tel: +4755 584214

20 Fax: +4755584450

21 


\section{Abstract}

23 Behavioural ecologists have for decades investigated the adaptive value of extra-

24 pair copulation (EPC) for females of socially monogamous species. Despite extensive

25 effort testing for genetic benefits, there now seems to be a consensus that the so-

26 called 'good genes' effects are at most weak. In parallel the search for direct benefits

27 has mostly focused on the period surrounding egg laying, thus neglecting potential

28 correlates of EPC that might be expressed at later stages in the breeding cycle. Here

29 we used Bayesian methods to analyse data collected over four years in a population

30 of blue tits (Cyanistes caeruleus), where no support was previously found for 'good

31 genes' effects. We found that broods with mixed paternity experienced less brood

32 failure at the nestling stage than broods with single paternity, and that females

33 having experienced complete brood failure in their previous breeding attempt had

34 higher rates of mixed paternity than either yearling or previously successful

35 females. To better understand these observations we also explored relationships

36 between extra-pair mating, male and female phenotype, and local breeding density.

37 We found that in almost all cases the sires of extra-pair offspring were close

38 neighbours, and that within those close neighbourhoods extra-pair sires were older

39 than other males not siring extra-pair offspring. Also, females did not display

40 consistent EPC status across years. Taken together our results suggest that multiple

41 mating might be a flexible female behaviour influenced by previous breeding

42 experience, and motivate further experimental tests of causal links between extra-

43 pair copulation and predation. 


\section{$45 \quad$ Keywords}

46 multiple mating, passerine bird, promiscuity

47

48 


\section{Introduction}

50 One way for a male of a socially monogamous species to increase his fitness is by

51 fertilizing extra-pair females, thus letting other males raise his extra-pair offspring

52 (Trivers 1972). Extra-pair copulation (EPC) and its outcome, extra-pair paternity

53 (EPP), are known to be widespread amongst socially monogamous birds (Griffith et

54 al. 2002). In such systems males are predicted to reduce their parental investment

55 when paternity in the nest is low or uncertain, and hence EPC is expected to

56 increase the reproductive burden for promiscuous females (Westneat and Sherman

57 1993, Kempenaers and Sheldon 1997, Arnqvist and Kirkpatrick 2005, Houston et al.

582005 , Schroeder et al. 2016). However, since EPC is a widespread strategy across

59 avian taxa, it has been suggested that benefits from EPC could be gained not only by

60 cuckolding males, but also by their female partners.

61 The observation that in many species females actively solicit extra-pair

62 copulations (Davies 1992, Kempenaers et al. 1992, Sheldon 1994a) further suggests

63 that EPCs might be (also) beneficial for females. Two main types of benefits for

64 females have been hypothesized, namely direct and indirect benefits. Tests of direct

65 benefits of EPC have mostly focused on precopulatory benefits (e.g. nuptial gifts) or

66 increased access to resources held by extra-pair males (e.g. Gray 1997), and have

67 been considered anecdotal in birds (Jennions and Petrie 2000, Griffith et al. 2002).

68 One other potential direct benefit of EPC is fertility insurance, whereby females

69 would maximise fertilisation success by obtaining extra-pair sperm to compensate

70 for infertility or sperm depletion of their social mates (Sheldon 1994b, Wedell et al. 
71 2002). Strikingly, direct benefits in terms of the contribution of extra-pair males to

72 post-hatching brood success have scarcely been investigated.

73 Indirect (genetic) benefits, on the other hand, have received much attention.

74 A main prediction is that if females seek EPC to increase the genetic 'quality' of their

75 offspring, then extra-pair offspring should have higher survival and/or reproductive

76 output than their within-pair half-siblings from the same nest. Although support for

77 such genetic benefits has been documented in some cases, the effect was found to be

78 weak at most (Akçay and Roughgarden 2007; but see Arct et al. 2015; Bowers et al.

79 2015), and a number of other studies found evidence of fitness costs - rather than

80 benefits - incurred by extra-pair offspring (Sardell et al. 2011, Hsu et al. 2014). All in

81 all, despite persistent interest, genetic benefits have received limited empirical

82 support. This has eventually led to an emerging consensus that although genetic

83 benefits may contribute through several weak mechanisms, they do not suffice to

84 explain the frequency and levels of EPP observed in natural populations (Arnqvist

85 and Kirkpatrick 2005, Charmantier and Sheldon 2006). It has also been suggested

86 that EPC in females may be better explained by non-adaptive mechanisms such as

87 genetic correlations between male and female behaviours, leading to indirect

88 selection on female promiscuity. However this is often not considered a satisfactory

89 general explanation for a phenomenon that is widespread both taxonomically and

90 across ecological settings (Arnold and Owens 2002; Griffith et al. 2002; reviewed in

91 Forstmeier et al. 2014).

$92 \quad$ Few studies of EPCs so far have explicitly considered that within-pair

93 offspring are not the only fitness component a male may influence through his 
94 behaviour. If males could, via some behavioural traits, contribute to the

95 reproductive success of their extra-pair females in addition to the parental

96 investment they provide at their own nests, these traits could be selected for

97 (Székely et al. 2013). One major cause of reproductive failure is brood failure, i.e. the

98 death of all nestlings. Despite the fact that brood failure can represent a potentially

99 strong selection pressure, it is underrepresented in behavioural studies of breeding

100 birds, mainly because observing or capturing breeding adults requires the presence

101 of live nestlings. This, combined with the strong focus on comparing within-pair to

102 extra-pair young in the search for indirect benefits, might explain why brood failure

103 has never been considered as a potential correlate of EPC.

104 There can be various causes for brood failure at the nestling stage, the

105 simplest being chick predation (Lima 2009). Predation on one of the parents can

106 also result in brood failure, because of the energetic challenge it represents for the

107 remaining parent to raise the brood alone. It is therefore not surprising that birds

108 display a wide range of antipredator strategies during breeding (Lima 2009). In

109 addition to alarm calls that may be perceived by neighbouring pairs as indicative of

110 the nearby presence of a predator, breeding adults can also join in collective

111 mobbing actions occurring in the neighbourhood (Caro 2005). In a number of small

112 passerine species, it was observed that the more individuals join the mob, the

113 sooner the predator tends to leave, and/or the longer it stays away (Hoogland and

114 Sherman 1976, Flasskamp 1994, Krams et al. 2010, Consla and Mumme 2012,

115 Grabowska-Zhang et al. 2012). Increasing the intensity of individual (e.g. alarm

116 calling) and collective (e.g. mobbing) antipredator behaviours might therefore be 
117 one mechanism through which males might enhance the post-hatching reproductive

118 success of neighbouring extra-pair females, without directly contributing to chick

119 provisioning (Eliassen and Jørgensen 2014, Sheldon and Mangel 2014).

120 Here we hypothesise that in such a case, broods having extra-pair sires in the

121 close neighbourhood would experience lower rates of post-hatching failure caused

122 by predation on chicks or on breeding adults. We explored this possibility in a

123 Mediterranean population of blue tits (Cyanistes caeruleus), where no clear evidence

124 was previously found for indirect (genetic) benefits of EPC (Charmantier and

125 Blondel 2003; Charmantier et al. 2004). In this population we identified events of

126 complete post-hatching brood failure that were directly or indirectly caused by

127 predation, and explored how their frequencies relate to mixed-paternity, as well as

128 to the proportion of extra-pair young (EPY) in the brood. We also assessed whether

129 individual females displayed repeatable EPP status across years, and whether

130 females having experienced brood failure displayed different levels of EPP

131 compared to previously successful females.

132 What we report here is an intriguing link between extra-pair mating and

133 both current and past brood failure. Given the results found, and in order to better

134 decipher what might explain them, we also tested for relationships between extra-

135 pair mating, male and female phenotype, and breeding density. More specifically, we

136 first explored the spatial range at which EPP was expressed, to better characterize

137 the pool of males that females may have chosen EP sires from. Within this spatial

138 range, we then tested whether EP sires differed from other potential mates in body

139 size, body weight, age, geographical distance or breeding synchrony, which may 
140 indicate whether certain male phenotypes were more likely to sire EP offspring.

141 Third, we tested whether females having EP offspring in their broods differed from

142 other females in body size, weight, age, laying date or clutch size. Finally, since

143 promiscuity may be affected by male availability (e.g. Charmantier and Perret

144 2004), we explored the links between two proxies of local breeding density and EPP.

\section{Materials and methods}

147 Study site and monitoring

148 We used data collected from 2000 to 2003 in a nestbox population of blue tits

149 located in the Rouvière oak woodland near Montpellier, Southern France $\left(43^{\circ} 40^{\prime} \mathrm{N}\right.$,

$150 \quad 03^{\circ} 40^{\prime}$ E, see Charmantier and Blondel 2003; Charmantier et al. 2004; Charmantier

151 and Perret 2004). Breeding events were monitored, and individuals were ringed

152 and measured using protocols described in e.g. Blondel et al. (2006). Blood samples

153 were collected from nestlings 5 to 9 days after hatching, and adults were captured

15410 to 15 days after hatching. There was no socially polygynous male in our sample.

155 Mixed paternity, i.e. the presence of EPY in broods was assessed in a total of 146

156 broods by comparing the genotypes of chicks (based on a set of seven microsatellite

157 markers, see Charmantier and Blondel 2003; Charmantier et al. 2004; Charmantier

158 and Perret 2004 for details) to that of the mother's social mate (i.e. the male

159 providing offspring care at her nest). There was no case of mismatch between

160 offspring and mother's genotype.

161

162 EPP rate and brood failure 
163 Field notebooks and databases were thoroughly checked to identify cases of post-

164 hatching brood failure (15 / 146), defined as death of all nestlings. No female in our

165 dataset experienced more than one such brood failure over the four years of the

166 study. Eight nests were not included in our sample because post-hatching failure

167 occurred either before the chicks were 5 days old ( 4 cases) or before the adults

168 could be captured ( 4 cases). We compared the frequencies of failure in mixed-

169 paternity vs single-paternity broods using a Bayesian generalized linear mixed-

170 effects model with brood failure as a binomial response variable, EPP status (i.e.

171 whether the brood had single or mixed paternity) and year as fixed effect factors,

172 and female identity (ID) as a random effect factor (MCMCgImm). We further

173 explored how the probability of brood failure related to the proportion of EPY in a

174 brood using a Bayesian generalized linear mixed-effects model with brood failure as

175 a binomial response variable, proportion of EPY and year as fixed effect factors, and

176 female ID as a random effect factor (MCMCgImm, see details below).

178 Previous breeding experience and current EPP

179 Focusing on those females that bred in two consecutive years over the four years of

180 the study ( $\mathrm{n}=81)$, we gathered information on EPP status $(n=42)$ and brood failure

$181(\mathrm{n}=81)$ in the previous breeding season. Paternity, and hence EPP status could not

182 be assigned for all years and all broods because not all males could be captured in

183 all years. To explore whether EPP status was consistent across years we tested

184 whether those females that previously had mixed-paternity broods had higher rates

185 of EPP than those having had single-paternity broods. We used a Bayesian 
186 generalized linear mixed-effects model with current EPP status as a response

187 variable, previous EPP status as a fixed effect factor, and year as a random effect

188 factor (MCMCgImm, see details below).

189 We also compared the frequencies of mixed paternity in broods of females

190 having previously experienced brood failure to those of previously successful

191 females. We used a Bayesian generalized linear mixed-effects model (MCMCglmm)

192 with EPP status as a response variable, previous breeding experience (failure or

193 success) as a fixed effect factor, and year as a random effect factor. Similarly we

194 compared EPP status between yearling females (i.e. reproductively naive) and

195 previously successful females.

197 Mapping neighbourhoods

198 Based on the GPS coordinates of nestboxes, and using Dirichlet tessellation, we

199 estimated territories as Thiessen polygons around each active nest box, as these

200 were shown to appropriately represent territory size in paridae (e.g. Wilkin et al.

201 2006). For territories at the edge of the study area, the outer border was defined so

202 that the nest was located at the centre of the territory. The edges of the study area

203 did not correspond to the edges of the forest (as only a portion of the forest was

204 equipped with nest boxes), and there was no obvious difference in EPP between

205 edge ( $n=63$ nests, 46\% EPP) and central ( $n=90$ nests, 48\% EPP) territories.

206 Excluding data from all edge nests would have resulted in a significant reduction of

207 our sample, and we therefore decided to include all territories in our sample. 
From the maps obtained for each study year, we then assigned the territories

209 surrounding each nest to one of four groups representing first, second, third, and 4+

210 order neighbours. First order neighbours are those nests sharing one territory

211 border with the focal brood; second (resp. third) order neighbours shared border

212 with the first (resp. second) order neighbours, and 4+ order neighbours consisted of

213 the remaining territories in the population. Broods with a hatching date posterior to

214 the date when the earliest brood in the population had fledged were excluded from

215 our analysis, so that our sample only consisted of nests with overlapping periods of

216 activity.

218 Spatial range of EPP

219 Across 146 broods, 69 (i.e. 47\%) were identified as mixed-paternity broods. Among

220 the 47 broods where paternity could be assigned to a known breeding male, 33 had

221 at least one EPY sired by first-order male neighbours. A remaining number of 10, 3,

222 and 1 broods had at least one EPY sired by second-, third-, and 4+-order male

223 neighbours, respectively (Figure 1). Consistent with earlier findings in this

224 population (Charmantier and Perret 2004), this indicates that EP sires are mainly

225 chosen from the close neighbourhood. For the rest of this study, we therefore

226 focused on first-order neighbourhoods as representing the main pool of potential EP

227 sires that females may have chosen from.

228

229

EP sires vs other first-order male neighbours 
230 We tested whether EP sires and other first-order male neighbours differed in terms

231 of male body size, weight, age, breeding asynchrony, and breeding distance to the

232 focal brood. The difference in egg-laying dates was used as a measure of breeding

233 asynchrony. Geographical distances were calculated from the GPS coordinates of

234 nest boxes. Tarsus length, measured to the nearest $0.1 \mathrm{~mm}$ with a calliper, was used

235 as a proxy for male body size. Body weight was measured to the nearest $0.1 \mathrm{~g}$ with a

236 Pesola spring scale. Male age (in years) was determined from plumage coloration at

237 first capture and from previous ring-marking records. We used minimum age at

238 capture for those birds that were first caught as adults. We randomly selected one

239 record for those individuals that were recorded in more than one year. To compare

240 EP sires with other first-order neighbours we used Bayesian estimation, as this

241 method is more powerful than classical t-tests (Kruschke 2013), via the online

242 version of "BEST" for two-sample comparisons, with 20000 burn-in steps and

243200000 iterations (Bååth 2012, see details below).

245 Females with mixed-paternity broods vs. other females

246 We tested whether females with mixed-paternity broods differed from other

247 females in body size, weight, age, laying date, or clutch size. Female body size,

248 weight, and age were measured as described for males, and laying date was defined

249 as the date when the first egg in a clutch was laid. We randomly selected one record

250 for those individuals that were recorded in more than one year. Comparisons were

251 carried out using Bayesian estimation (BEST, Bååth 2012, see details below). 


\section{EPP rate and local breeding density}

254 Two different proxies for density were used, namely the number of first-order

255 neighbours (ranging from 2 to 9) and the mean distance to first-order neighbours

256 (ranging from $57.1 \mathrm{~m}$ to $238 \mathrm{~m}$ ). To explore whether density might be related to

257 EPP, we compared these two proxies between mixed-paternity and single-paternity

258 broods using Bayesian estimation as above (BEST, Bååth 2012 see details below).

259 For each study year we also tested for spatial autocorrelation in EPP occurrence,

260 which might indicate clustering in EPP events, using Moran's I (ape library, R 3.2.3,

261 R Core Team 2015). Since Moran's I was never significant (see results) further

262 analyses were performed assuming no spatial autocorrelation.

263 For all two-sample comparisons using BEST the burn-in period was 20000

264 and the number of iterations 200000 (Bååth 2012).For all Bayesian estimation

265 analyses using MCMCgImm (MCMCgImm library in R 3.2.3, R Core Team 2015),

266 family was defined as "categorical" and residual variance at the limit was set to 1.

267 The random effect variance structure $(G)$ used in the prior included a variance set to

2681 and a degree of belief (nu) set to 0.002 . The number of iterations and thinning

269 interval were defined so that the effective sample size was 1000 or more, while

270 keeping autocorrelation between successive samples below 0.1 (Hadfield 2017). For

271 almost all models the thinning interval was 200 and the number of iterations

272300000 (except for the model with proportion of EPY as dependent variable, for

273 which the thinning interval was 200 and the number of iterations 600000).

274 Convergence of the models was assessed by visual inspection of traces. 


\section{Results}

277 EPP rate and brood failure

278 Mixed-paternity broods experienced complete brood failures less frequently than

279 single-paternity broods (mixed: 3/69; single: 12/77; MCMCgImm: $P=0.0 \underline{2} 3$; Table

280 1A). In addition, brood failure occurrence decreased with increasing proportions of

281 EPY (MCMCglmm: $P=0.012$; Table 1B).

283 Previous breeding experience and current EPP

284 The probability of mixed paternity in a current year did not differ between females 285 that previously had mixed-paternity broods (10/22) and those that previously had 286 single-paternity broods (12/19) (MCMCgImm: $\mathrm{P}=0.17$; Table 2), suggesting low 287 repeatability of mixed paternity for females. However, females having previously 288 experienced complete brood failures had mixed-paternity broods more often $(9 / 11)$ 289 than previously successful females (32/70) (MCMCglmm: $\mathrm{P}=0.02$; Table 2), while 290 the latter did not differ in EPP status from inexperienced (yearling) females (29/63)

291 (MCMCglmm: $\mathrm{P}=0.979$; Table 2; Figure 2).

293 EP sires vs. other first-order male neighbours

294 Within first-order neighbourhoods of mixed-paternity broods, there was no 295 difference between EP sires $(n=24)$ and other males $(n=60)$ in body size, weight, 296 breeding asynchrony, or geographical distance (all 95\% highest-density intervals 297 included zero, Table 3A). EP sires were, however, older than other first-order male 298 neighbours (BEST; Table 3A). 
$300 \quad$ Females with mixed-paternity broods vs. other females

301 Females with mixed-paternity broods $(n=45)$ did not differ from other females

$302(\mathrm{n}=57)$ in body size, weight, age, laying date or clutch size (all 95\% highest density

303 intervals included zero; BEST; Table 3B).

304

305 EPP rate and local breeding density

306 Neither the number of first-order neighbours, nor the mean distance to first-order

307 neighbours, differed between mixed-paternity and single-paternity broods (BEST,

308 Table 4). In addition, in none of the study years was there any statistically

309 significant spatial autocorrelation in EPP occurrence (Moran's I; year 2000, $P=0.83$;

$3102001, P=0.49 ; 2002, P=0.48 ; 2003, P=0.87)$.

\section{Discussion}

313 In this study we found a combination of patterns that, taken together, cannot be

314 fully explained by current hypotheses of the benefits of EPC for females. We indeed

315 found reduced brood failure in mixed-paternity broods compared to broods sired by

316 a single male, and a negative relation between brood failure and the proportion of

317 EPY in broods. Furthermore, in the same population no difference in age,

318 morphometrics, or condition was previously found between cuckolded and non-

319 cuckolded males, nor between cuckolded and cuckolding males, and no difference in

320 survival or recruitment was revealed between WP and EP offspring (Charmantier et

321 al. 2004). The 'good genes' hypothesis therefore does not seem supported in this 
322 population, and more importantly, 'good genes' effects could not explain why all

323 nestlings in a brood would survive better, regardless of the genes they may carry,

324 when the brood is sired by more than one male. Finally, given the common

325 expectation that cuckolded males should provide less care and protection for their

326 brood due to low paternity (but see Schroeder et al. 2016), our observations require

327 alternative explanations.

328 A first tentative explanation for the difference in brood failure between

329 brood types is that areas differed in both resource availability and extra-pair

330 mating, with extra-pair mating higher in areas of high food abundance or low

331 predation risk. Yet, while spatial autocorrelation in habitat types (Szulkin et al.

332 2015) and in fitness (Marrot et al. 2015) are present in this population, our dataset

333 revealed no spatial autocorrelation in EPP occurrence or brood failure, and no effect

334 of breeding density on EPP status within first-order neighbourhoods, suggesting

335 that extra-pair mating occurred independently of local habitat quality (but see

336 Charmantier and Perret 2004 for effects at larger spatial scales). Second, we

337 hypothesized that variation in behaviour or other characteristics of males or

338 females could influence both EPP occurrence and failure rate. For example, if

339 multiply mating females had higher body condition, longer breeding experience, or

340 specific behavioural types, this could translate into higher brood success (van Oers

341 et al. 2004, Patrick et al. 2012). While we did not find any difference in age, body

342 size, body condition, or breeding phenology between mothers of mixed-paternity

343 broods and those of single-paternity broods, we did however not directly measure

344 their behaviour, and cannot rule out that they might have differed in some other 
345 traits. This might also apply to males, and in particular the link between male 346 propensity to loose paternity and the level of protection and care received by their

347 brood (e.g. Patrick et al. 2012; Schroeder et al. 2016), is an aspect that would 348 require further investigation.

349 However, differences in behavioural traits alone would not suffice to explain 350 why older male neighbours would sire more EP offspring, irrespective of other

351 phenotypic traits. One potential explanation is that in case of selective

352 disappearance (Bouwhuis et al. 2009), male age might reflect male genetic quality,

353 with older males being those better able to survive, and hence that EPP would be

354 driven by a combination of personality and good genes effects. In the absence of any

355 differences in survival or recruitment rate between WP and EP offspring

356 (Charmantier et al. 2004), however, this explanation appears unlikely.

357 Even though our results remain correlative, they tend to suggest that

358 females, by engaging in EPC with their close neighbours, would gain some protective

359 advantage to their brood. Older males are potentially also those with the longest

360 local breeding experience, and hence may be better able to warn the neighbourhood

361 against predators or interact with neighbours in other beneficial ways. We also

362 found that previous experience of complete, post-hatching brood failure by females

363 was associated with a higher frequency of EPP, as compared to either

364 unexperienced or previously successful females. This suggests that EPC may be a

365 flexible female behaviour. Taken together our results suggest that EPP may confer a

366 direct benefit in terms of decreased brood failure, perhaps via increased vigilance, 
367 mobbing, or other behaviours through which neighbouring adults may contribute

368 even though they do not participate in chick provisioning.

369 When breeding pairs, and particularly yearling individuals, settle in a

370 territory there might be insufficient environmental cues available to accurately

371 assess risk of future failure. If this risk is perceived during the fertile period, it

372 follows from our reasoning that one way for females to respond would be by

373 seeking more EPC. If the risk of failure is perceived after the end of the fertile period,

374 such an immediate response becomes impossible, and females could benefit not

375 only from moving to a safer site (e.g. Danchin et al. 1998, Doligez et al. 2004), but

376 also from altering their mating strategy in their next breeding attempt (Lima 2009).

377 Experimental tests would be needed to establish a causal link between perceived

378 risk of failure and EPP rate, and we are currently exploring this further. If true, this

379 hypothesis might help explain why EPP seems to have low repeatability for females,

380 not only in our study population, but also in other species (I. Winney, pers. comm.;

381 Reid et al. 2011).

382 In our study population, the main predators on blue tit chicks are mustelids

383 like the weasel Mustela nivalis and the common genet Genetta genetta (that learned

384 to open Schwegler nestboxes from the front), while the main predator on adults is

385 the Eurasian sparrowhawk Accipiter nisus. Brood failures resulted either from brood

386 predation, i.e. disappearance of all nestlings from a nest box prior to day 15 (five

387 cases), or corresponded to cases when one breeding adult disappeared shortly after

388 having been observed feeding a brood with nestlings in good condition, and was

389 never recorded again (i.e. in the 12 years following the end of the present study). We 
390 could infer that an individual was missing when it was previously caught and ringed

391 (between 11 and 14 days post-hatching), but not observed again when the chicks

392 were measured at day 15 post-hatching (the presence and number of adults

393 alarming was systematically noted). Even though we cannot provide definitive

394 evidence, for such cases we assume that death by predation is the most likely cause

395 of disappearance (10 cases). This assumption seems supported by recent

396 observations in another population of blue tits, where almost all cases of complete

397 brood failure were related to sudden and permanent disappearance of one of the

398 parents; in those cases the missing parent was recorded (via automated

399 monitoring) active at the nest up to the point where it disappeared, which points to

400 predation as the most likely cause of disappearance (Santema and Kempenaers,

401 unpublished results). But even assuming that nest desertion might explain some of

402 the failing broods, our observations contradict the common assumption that males

403 should be more prone to desertion of those broods where paternity is shared

404 (Trivers 1972, Houston and McNamara 2002). Here we observe the opposite, i.e.

405 that broods with single paternity are more prone to failure. In addition, as far as we

406 can observe in our sample, EPP rate was not linked to pair-bond stability, as the

407 frequency of mixed paternity did not vary between pairs that divorced and both

408 individuals bred again separately (19 cases, 42\% EPP), and those that remained

409 stable (18 cases, 44\% EPP). Noticeably, and irrespective of brood failure, EPP rate

410 was found higher in cases where the previous male partner was never found again

411 (33 cases, 61\% EPP). Finally, we did not find any relation between EPP and two

412 measures of local breeding density, which tends to contradict the assumption that 
413 EPC might simply emerge from high local availability of mating partners. Our

414 hypothesis, i.e. that broods sired by multiple males would gain overall better success

415 through post-copulatory mechanisms, therefore appears as the most parsimonious

416 explanation given the set of patterns of EPP and complete brood failure (likely due

417 to predation) in this population.

418 Identification of individuals in traditionally monitored passerine populations

419 usually requires the recapture of ring-marked birds, which may lead to sampling

420 bias because some individuals (e.g. early-failing breeders) have very low detection

421 probabilities (Kidd et al. 2015). Fortunately, an increasing number of bird

422 populations are now equipped with devices allowing automated or remote

423 detection of individuals (e.g. Aplin et al. 2012; Farine et al. 2015), and this will make

424 it easier to study brood failure and extra-pair behaviour of males and females. For

425 example, a recent study using passive integrative transponder (PIT) tags showed

426 that both male and female blue tits made frequent forays in the territories of their

427 first-order neigbhours throughout the breeding season, which suggests that close

428 neighbours interact in a number of ways that yet remain to be investigated (Schlicht

429 et al. 2015).

430 A fundamental limitation of our study is the correlative nature of the results.

431 We do not claim to be providing definitive support for a causal link between EPP

432 and predation, yet the intriguing observations reported here are consistent with it

433 when taken together, while they cannot be fully explained by current alternative

434 hypotheses. Similar evidence from other populations as well as field experiments

435 such as manipulations of predator risk assessment are now required. This study 
436 illustrates the idea that focusing on brood failure might yield overlooked insights,

437 and that all possible ecological benefits of EPC might not have been fully explored 438 yet.

\section{Acknowledgements}

441 We thank Philippe Perret, Jacques Blondel and Marcel Lambrechts for assistance on

442 the field, as well as all other students, postdocs and fieldworkers who collected data

443 in the Rouvière study site in 2000-2003. Thanks to Göran Högstedt, Adriana

444 Maldonado Chaparro, and Kristina Beck for providing feedback on earlier drafts of

445 this manuscript. We are also grateful for constructive comments from two

446 anonymous referees. AC was funded by the European Research Council (Starting

447 grant ERC-2013-StG-337365-SHE to AC) and the OSU OREME. SE, CJ and AM were

448 funded by the Research Council of Norway (grant 222021/F20). All applicable

449 national guidelines for the care and use of animals were followed, and all

450 procedures performed were in accordance with the ethical standards of the

451 institution at which the studies were conducted.

\section{References}

454 Akçay, E. and Roughgarden, J. 2007. Extra-pair paternity in birds: Review of the genetic benefits. - Evol. Ecol. Res. 9: 855-868. Aplin, L. M., Farine, D. R., Morand-Ferron, J. and Sheldon, B. C. 2012. Social networks predict patch discovery in a wild population of songbirds. - Proc. R. Soc. B Biol. Sci. 279: 4199-4205.

Arct, A., Drobniak, S. M. and Cichoń, M. 2015. Genetic similarity between mates predicts extrapair paternity-a meta-analysis of bird studies. - Behav. Ecol. 26: 959-968.

Arnold, K. E. and Owens, I. P. F. 2002. Extra-pair paternity and egg dumping in birds: life history, parental care and the risk of retaliation. - Proc. R. Soc. B Biol. Sci. 
269: 1263-1269.

Arnqvist, G. and Kirkpatrick, M. 2005. The evolution of infidelity in socially monogamous passerines: the strength of direct and indirect selection on extrapair copulation behavior in females. - Am. Nat. 165 Suppl: S26-S37. Bååth, R. 2012. Bayesian estimation Supersedes the t-test (BEST) - online. http://www.sumsar.net/best_online/

Blondel, J., Thomas, D. W., Charmantier, A., Perret, P., Bourgault, P. and Lambrechts, M. M. 2006. A Thirty-Year Study of Phenotypic and Genetic Variation of Blue Tits in Mediterranean Habitat Mosaics. - Bioscience 56: 661.

Bouwhuis, S., Sheldon, B. C., Verhulst, S. and Charmantier, A. 2009. Great tits growing old: selective disappearance and the partitioning of senescence to stages within the breeding cycle. - Proc. Biol. Sci. 276: 2769-77.

Bowers, E. K., Forsman, A. M., Masters, B. S., Johnson, B. G. P., Johnson, L. S., Sakaluk, S. K. and Thompson, C. F. 2015. Increased extra-pair paternity in broods of aging males and enhanced recruitment of extra-pair young in a migratory bird. - Evolution (N. Y). 69: 2533-2541.

Caro, T. 2005. Antipredator defenses in birds and mammals. - University of Chicago Press.

Charmantier, A. and Blondel, J. 2003. A Contrast in Extra-Pair Paternity Levels on Mainland and Island Populations of Mediterranean Blue Tits. - Ethology 109: 351-363.

Charmantier, A. and Perret, P. 2004. Manipulation of nest-box density affects extrapair paternity in a population of blue tits (Parus caeruleus). - Behav. Ecol. Sociobiol. 56: 360-365.

Charmantier, A. and Sheldon, B. C. 2006. Testing genetic models of mate choice evolution in the wild. - Trends Ecol. Evol. 21: 417-9.

Charmantier, A., Blondel, J., Perret, P. and Lambrechts, M. M. 2004. Do extra-pair paternities provide genetic benefits for female blue tits Parus caeruleus ? - J. Avian Biol. 35: 524-532.

Consla, D. J. and Mumme, R. L. 2012. Response of Captive Raptors to Avian Mobbing Calls: the Roles of Mobber Size and Raptor Experience. - Ethology 118: 10631071.

Danchin, E., Boulinier, T. and Massot, M. 1998. Conspecific Reproductive Success and Breeding Habitat Selection : Implications for the Study of Coloniality. - Ecology 79: 2415-2428.

Davies, N. B. 1992. Dunnock behaviour and social evolution. - Oxford University Press.

Doligez, B., Pärt, T. and Danchin, E. 2004. Prospecting in the collared flycatcher: Gathering public information for future breeding habitat selection? - Anim. Behav. 67: 457-466.

Eliassen, S. and Jørgensen, C. 2014. Promiscuity and evolution of cooperative neighbourhoods. - PLoS One 9: e99878.

Farine, D. R., Aplin, L. M., Sheldon, B. C. and Hoppitt, W. 2015. Interspecific social networks promote information transmission in wild songbirds. - Proc. Biol. Sci. 282: 20142804.

Flasskamp, A. 1994. The Adaptive Significance of Avian Mobbing V. An Experimental 
Test of the "Move On" Hypothesis. - Ethology 96: 322-333.

511

512

513

514

515

516

517

518

519

520

521

522

523

524

525

526

527

528

529

530

531

532

533

534

535

536

537

538

539

540

541

542

543

544

545

546

547

548

549

550

551

552

553

554

555

Forstmeier, W., Nakagawa, S., Griffith, S. C. and Kempenaers, B. 2014. Female extrapair mating: adaptation or genetic constraint? - Trends Ecol. Evol. 29: 456-64.

Grabowska-Zhang, A. M., Sheldon, B. C. and Hinde, C. A. 2012. Long-term familiarity promotes joining in neighbour nest defence. - Biol. Lett. 8: 544-6.

Gray, E. 1997. Female red-winged blackbirds accrue material benefits from copulating with extra-pair males. - Anim. Behav.: 625-639.

Griffith, S. C., Owens, I. P. F. and Thuman, K. A. 2002. Extra pair paternity in birds: A review of interspecific variation and adaptive function. - Mol. Ecol. 11: 21952212.

Hadfield, J. 2017. MCMCglmm course notes. See http://cran. r-project. org/web/packages/MCMCglmm/vignettes/CourseNotes.pdf. in press.

Hoogland, J. L. and Sherman, P. W. 1976. Advantage and disadvantages of bank swallow (Riparia riparia) coloniality. - Ecol. Monogr. 46: 33-58.

Houston, A. I. and McNamara, J. M. 2002. A self-consistent approach to paternity and parental effort. - Philos. Trans. R. Soc. London B Biol. Sci.: 351-362.

Houston, A., Székely, T. and McNamara, J. M. 2005. Conflict between parents over care. - Trends Ecol. Evol. 20: 33-38.

Hsu, Y. H., Schroeder, J., Winney, I., Burke, T. and Nakagawa, S. 2014. Costly infidelity: Low lifetime fitness of extra-pair offspring in a passerine bird. Evolution (N. Y). 68: 2873-2884.

Jennions, M. D. and Petrie, M. 2000. Why do females mate multiply? A review of the genetic benefits. - Biol. Rev. Camb. Philos. Soc. 75: 21-64.

Kempenaers, B. and Sheldon, B. C. 1997. Studying paternity and paternal care: pitfalls and problems.: 423-427.

Kempenaers, B., Verheyen, G. R., Van den Broeck, M., Burke, T., Van Broeckhoven, C. and Dhondt, A. A. 1992. Extra-pair paternity results from female preference for high-quality males in the blue tit. - Nature 357: 494-496.

Kidd, L. R., Sheldon, B. C., Simmonds, E. G. and Cole, E. F. 2015. Who escapes detection? Quantifying the causes and consequences of sampling biases in a long-term field study. - J. Anim. Ecol. 84: 1520-1529.

Krams, I., Bërziņš, A., Igaune, K. and Rantala, M. J. 2010. The increased risk of predation enhances cooperation. 277: 513-518.

Kruschke, J. K. 2013. Bayesian Estimation Supersedes the t Test. - J. Exp. Psychol. Gen. 142: 573-603.

Lima, S. L. 2009. Predators and the breeding bird: Behavioral and reproductive flexibility under the risk of predation. - Biol. Rev. 84: 485-513.

Marrot, P., Garant, D. and Charmantier, A. 2015. Spatial autocorrelation in fitness affects the estimation of natural selection in the wild. - Methods Ecol. Evol. 6: 1474-1483.

Patrick, S. C., Chapman, J. R., Dugdale, H. L., Quinn, J. L. and Sheldon, B. C. 2012. Promiscuity, paternity and personality in the great tit. - Proc. Biol. Sci. 279: 1724-30.

R Core Team 2015. R: A language and environment for statistical computing. R Foundation for Statistical Computing, Vienna, Austria. in press.

Reid, J. M., Arcese, P., Sardell, R. J. and Keller, L. F. 2011. Heritability of female extra- 
582

583

584

585

586

587

588

589

590 pair paternity rate in song sparrows (Melospiza melodia). - Proc. Biol. Sci. 278: 1114-20.

Sardell, R. J., Arcese, P., Keller, L. F. and Reid, J. M. 2011. Sex-specific differential survival of extra-pair and within-pair offspring in song sparrows, Melospiza melodia. - Proc. R. Soc. B Biol. Sci. 278: 3251-3259.

Schlicht, L., Valcu, M. and Kempenaers, B. 2015. Male extraterritorial behavior predicts extrapair paternity pattern in blue tits, Cyanistes caeruleus. - Behav. Ecol. 26: 1404-1413.

Schroeder, J., Hsu, Y.-H., Winney, I., Simons, M. J. P., Nakagawa, S. and Burke, T. 2016. Predictably philandering females prompt poor paternal provisioning. - Am. Nat. online ear: 000-000.

Sheldon, B. C. 1994a. Sperm competition in the chaffinch: the role of the female. Anim. Behav. 47: 163-173.

Sheldon, B. C. 1994b. Male Phenotype, Fertility, and the Pursuit of Extra-Pair Copulations by Female Birds. - Proc. R. Soc. B Biol. Sci. 257: 25-30.

Sheldon, B. C. and Mangel, M. 2014. Love thy neighbour. 512: 381-382.

Székely, T., Remeš, V., Freckleton, R. P. and Liker, A. 2013. Why care? Inferring the evolution of complex social behaviour. - J. Evol. Biol. 26: 1381-1391.

Szulkin, M., Zelazowski, P., Marrot, P. and Charmantier, A. 2015. Application of high resolution satellite imagery to characterize individual-based environmental heterogeneity in a wild blue tit population. - Remote Sens. 7: 13319-13336.

Trivers, R. L. 1972. Parental investment and sexual selection. - In: Campbell, B. (ed), Sexual selection and the Descent of Man, 1871-1971. Aldine-Atherton, in press.

van Oers, K., Drent, P. J., de Goede, P. and van Noordwijk, A. J. 2004. Realized heritability and repeatability of risk-taking behaviour in relation to avian personalities. - Proc. Biol. Sci. 271: 65-73.

Wedell, N., Gage, M. J. G. and Parker, G. A. 2002. Sperm competition, male prudence, and sperm-limited females. - Trends Ecol. Evol. 17: 313-320.

Westneat, D. F. and Sherman, P. W. 1993. Parentage and the evolution of paternal care. - Behav. Ecol. 4: 66-77.

Wilkin, T. A., Garant, D., Gosler, A. G. and Sheldon, B. C. 2006. Density effects on lifehistory traits in a wild population of the great tit Parus major: Analyses of longterm data with GIS techniques. - J. Anim. Ecol. 75: 604-615. 
591 Figure 1. Distribution of the spatial distances between EP offspring and the

592 corresponding EP sires (see Methods for a definition of the four distance classes).

593

594 Figure 2. Mixed paternity in relation to the experience of females (success or failure

595 of their previous brood). Yearling females have no reproductive experience. The

596 number of broods in each group is indicated, and letters indicate credible

597 differences between the groups (MCMCglmm, see Methods).

598 
599 Figure 1

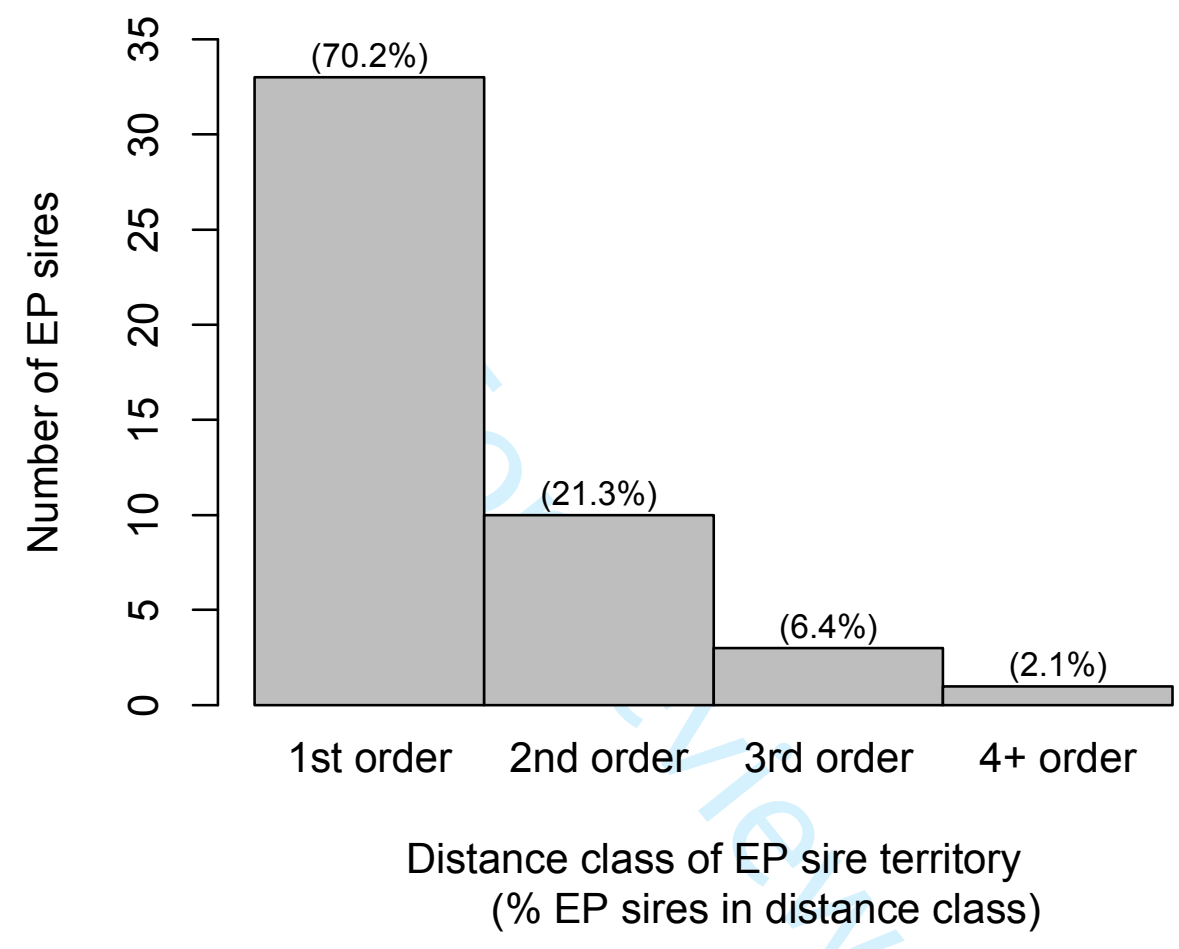

600

601

602 


\section{Figure 2}

604

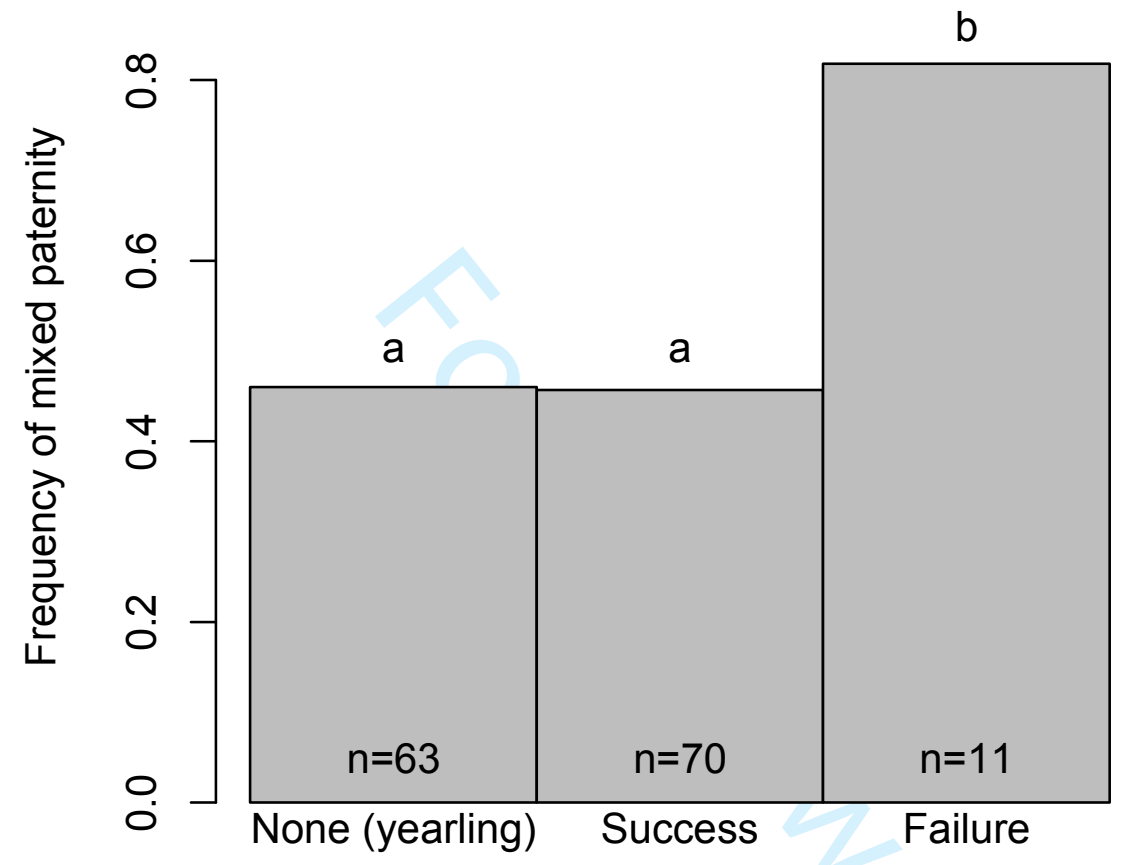

Outcome of previous brood

605

606 


\begin{tabular}{|c|c|c|c|c|c|}
\hline & $\begin{array}{l}\text { Posterior } \\
\text { mean }\end{array}$ & $\begin{array}{l}\text { Lower 95\% } \\
\text { CI }\end{array}$ & $\begin{array}{l}\text { Upper 95\% } \\
\text { CI }\end{array}$ & $\begin{array}{l}\text { Effective sample } \\
\text { size }\end{array}$ & $\mathrm{P}$ \\
\hline \multicolumn{6}{|c|}{ A. EPP status } \\
\hline EPP status & $-1 . \underline{1} 62$ & $-3.08 z 2$ & $-0.1 \underline{9} \theta$ & $1 \underline{334174}$ & $0.0 \underline{18} 3$ \\
\hline Year & $-0.5 \underline{7} 6$ & $-1.1 \underline{3} 6$ & $-0.0 \underline{21}$ & $1 \underline{368485}$ & $0.05 \underline{1}$ \\
\hline \multicolumn{6}{|c|}{ B. Proportion EPY } \\
\hline $\begin{array}{l}\text { Proportion } \\
\text { of EPY }\end{array}$ & $-6 . \underline{968}$ & -13.8516 & $-0 . \underline{68} 07$ & $1 \underline{150004}$ & $0.0 \underline{12}$ \\
\hline Year & -0.57 & $-1.1 \underline{67}$ & $0.0 \underline{4} 05$ & $2 \underline{985008}$ & $0.0 \underline{546}$ \\
\hline
\end{tabular}

607

608 Table 1. Results of Bayesian generalized linear mixed-effects models (MCMCgImm)

609 explaining the probability of complete post-hatching brood failure in relation to

610 either (A) the EPP status of broods (mixed $v s$ single paternity) or (B) the proportion

611 of EPY in broods. See Methods.

612 


\begin{tabular}{|c|c|c|c|c|c|}
\hline & $\begin{array}{l}\text { Posterior } \\
\text { mean }\end{array}$ & $\begin{array}{l}\text { Lower 95\% } \\
\text { CI }\end{array}$ & $\begin{array}{l}\text { Upper } 95 \% \\
\text { CI }\end{array}$ & $\begin{array}{l}\text { Effective sample } \\
\text { size }\end{array}$ & $\mathrm{P}$ \\
\hline A. Past EPP & $-1.1 \underline{76}$ & -2.8679 & $0 . \underline{5860}$ & $1 \underline{485290}$ & $0.17 \underline{4}$ \\
\hline $\begin{array}{l}\text { B. Past } \\
\text { failure }\end{array}$ & $2.1 \underline{6} 7$ & $0 . \underline{1733}$ & 4.234 & $1 \underline{11} 485$ & $0.0 \underline{192}$ \\
\hline $\begin{array}{l}\text { C. } \\
\text { Experience }\end{array}$ & $-0.00 \underline{4} 6$ & $-0 . \underline{7881}$ & 0.9285 & 1485 & 0.9749 \\
\hline
\end{tabular}

613

614 Table 2. Results of Bayesian generalized linear mixed-effects models (MCMCgImm,

615 see Methods) explaining the probability of mixed paternity in broods of a current

616 year in relation to (A) the EPP status of the same female's brood the previous year,

617 (B) brood outcome in the previous year (fledging vs complete post-hatching brood

618 failure), or (C) breeding experience of the female (either yearling or having

619 previously fledged a brood).

620

621

622 


\begin{tabular}{|c|c|c|c|c|}
\hline & Mea & $1 \pm S D$ & & HDI \\
\hline & & & Min & $\operatorname{Max}$ \\
\hline A. Males & $\begin{array}{l}\text { EP sires } \\
(n=24)\end{array}$ & $\begin{array}{l}\text { Other males } \\
(\mathrm{n}=60)\end{array}$ & & \\
\hline Tarsus length (mm) & $16.86 \pm 0.39$ & $16.90 \pm 0.41$ & -0.15 & 0.25 \\
\hline Body weight (g) & $10.82 \pm 0.43$ & $11.10 \pm 0.53$ & -0.01 & 0.46 \\
\hline Age (y) & $2.21 \pm 0.98$ & $1.93 \pm 1.40$ & -1.52 & -0.73 \\
\hline Breeding synchrony (d) & $0.38 \pm 7.96$ & $1.93 \pm 8.20$ & -2.24 & 5.54 \\
\hline Distance to brood (m) & $133.64 \pm 74.19$ & $107.67 \pm 43.38$ & -58.1 & 9.99 \\
\hline B. Females & $\begin{array}{l}\text { With EPY } \\
(n=45)\end{array}$ & $\begin{array}{l}\text { Without EPY } \\
(\mathrm{n}=57)\end{array}$ & & \\
\hline Tarsus length (mm) & $16.43 \pm 0.42$ & $16.49 \pm 0.55$ & -0.26 & 0.13 \\
\hline Body weight (g) & $11.04 \pm 0.48$ & $10.92 \pm 0.60$ & -0.10 & 0.34 \\
\hline Age (y) & $1.76 \pm 1.05$ & $1.61 \pm 0.82$ & -0.26 & 0.49 \\
\hline Laying date $(\mathrm{d})$ & $35.51 \pm 5.43$ & $34.86 \pm 5.76$ & -2.03 & 3.37 \\
\hline Clutch size & $9.71 \pm 1.68$ & $9.77 \pm 1.50$ & -0.71 & 0.55 \\
\hline
\end{tabular}

625

626 Table 3. Comparison of EP sires with other first-order male neighbours of mixed-

627 paternity broods (A), and of females with and without EPY (B). The 95\% highest 628 density interval (HDI) represents the credible interval of the difference in means 
629 between the groups. EP sires were older than other first order, male neighbours of

630 mixed-paternity broods. There was no credible difference in any of the other male 631 or female variables, since all other 95\% HDIs included zero (BEST, see Methods). 632 


\begin{tabular}{|l|l|l|l|l|}
\hline \multirow{2}{*}{} & \multicolumn{2}{|c|}{ Mean \pm SD } & \multicolumn{2}{c|}{$95 \%$ HDI } \\
\cline { 2 - 6 } & With EPP (n=69) & No EPP & Min & Max \\
& & $(\mathrm{n}=77)$ & & \\
\hline Number of neighbours & $4.63 \pm 1.58$ & $4.76 \pm 1.34$ & -0.34 & 0.63 \\
\hline Mean distance to neighbours (m) & $114.03 \pm 38.34$ & $107.00 \pm$ & -19.6 & 5.43 \\
& & 39.01 & & \\
\hline
\end{tabular}

634 Table 4. Breeding density (as represented by two different proxies) in first-order

635 neighbourhoods of mixed-paternity (with EPP) and single-paternity broods (no

636 EPP). The 95\% highest density interval (HDI) represents the credible interval of the

637 difference in means between the groups. Both 95\% HDIs included zero, which

638 means that there was no credible difference in breeding density (BEST, see

639 Methods).

640 


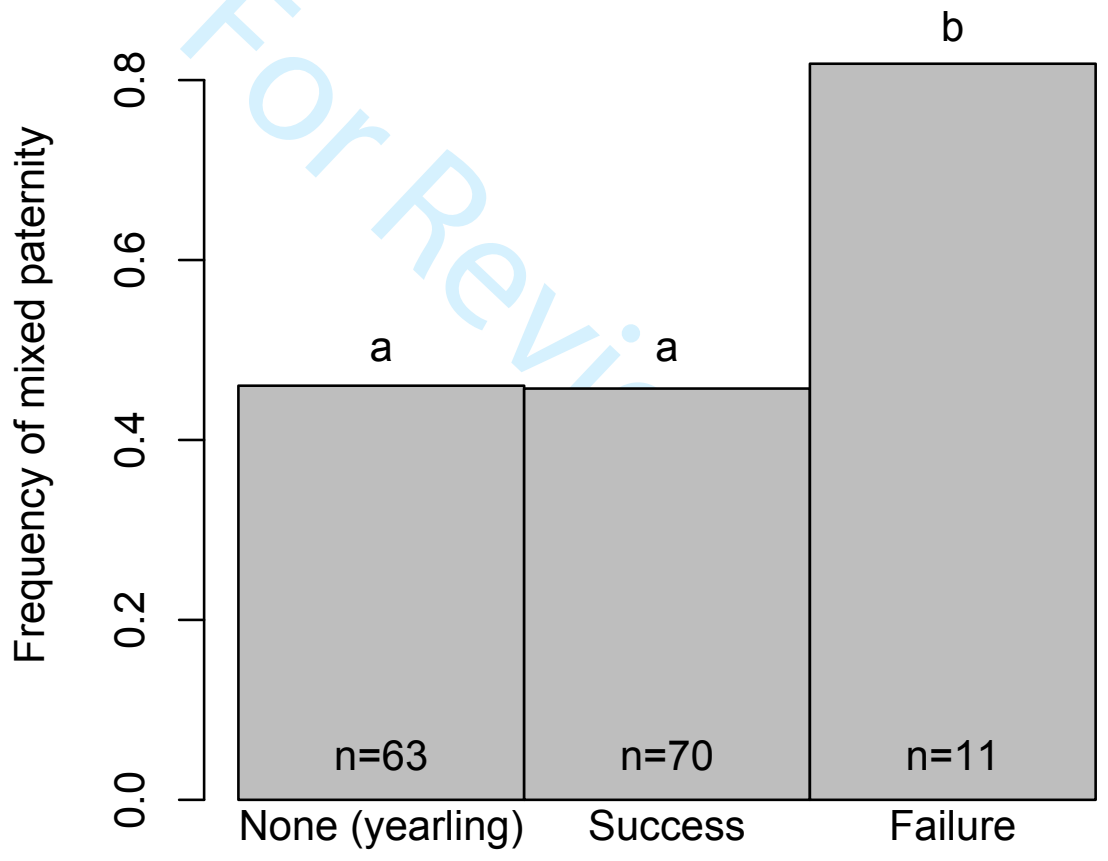

Outcome of previous brood 